\title{
Electrodeposition of Tungsten Alloys Containing Iron, Nickel, and Cobalt
}

\author{
By Abner Brenner, Polly Burkhead, and Emma Seegmiller
}

\begin{abstract}
Methods of electrodepositing tungsten alloys with metals of the iron group have been developed. Some of the properties of the alloys have been determined and indicate that the alloys may be of commercial value. The plating solutions consist essentially of the appropriate metal salts, together with salts of certain hydroxy-organic acids in ammoniacal solutions at a $\mathrm{pH}$ of about 8.5. The deposits are smooth, strong, and brittle. The nickel and cobalt alloys become ductile on heating. As plated, the nickel and cobalt alloys have a hardness of 350 to 700 Vickers, and the iron alloy, 700 to 900 Vickers. The alloys undergo precipitation hardening and the cobalt-tungsten alloys retain their hardness when hot.
\end{abstract}

\section{Introduction}

This report covers methods of codepositing tungsten with iron, nickel, or cobalt and the study of the properties and applications of these alloys. A comprehensive research was conducted by a number of persons over a period of several years, during which hundreds of plating baths and deposits were prepared and studied. Although this investigation is not complete, it is advisable to publish the results thus far obtained in order to permit others to determine the commercial applicability of the alloys, and to conduct further studies.

Methods have been worked out for electrodepositing alloys of tungsten with iron, cobalt, or nickel. "Some of the measured properties indicate that these alloys may be suitable for certain engineering applications. The plating solutions consist essentially of the appropriate metal salts, together with salts of certain hydroxy-organic acids in ammoniacal solutions at a $\mathrm{pH}$ of about 8.5. Deposits as thick as several hundredths of an inch can be made with good current efficiency. They are smooth, strong, and hard, and some show precipitation hardening.

\section{Experiments With Published Baths}

\section{Deposition of Alloys From Acid Solutions}

When this investigation was started, most of the published work on depositions of tungsten alloys dealt with acid baths. Between 1935 and 1940 , interest was aroused in this subject, especially the nickel-tungsten alloys. Harry H. Armstrong and Arthur B. Menefee [1 to 8$]^{1}$ patented a process and organized the Tungsten Electrodeposit Corporation. Their patents emphasized the use of fluorides in acid baths. M. L. Holt and his coworkers [17, 18, 19] published papers on the electrodeposition of tungsten with nickel, iron, and cobalt.

When the work of these investigators was repeated, deposits were obtained that contained the reported proportions of tungsten, but they had inferior physical properties, being weak and brittle, and appeared to contain oxide. Deposits more than a thousandth of an inch thick were rough, and the cathode current efficiencies were low.

In addition to trying the solutions of published composition experiments were made with acid baths containing the tungsten as complex ions, such as borotungstates, phosphotungstates, or fluotungstates. The deposits obtained from these solutions were not superior to those obtained from the simple Holt bath. The only advantage of the complex formation was that it permitted larger concentrations of tungsten to be held in solution (as compared with the few grams permissible in the Holt bath) so that the control of the composition of the bath was not critical.

In all the acid baths "tungsten blue," containing

\footnotetext{
${ }^{1}$ Figures in brackets indicate the iterature references at the end of this paper.
} 
compounds of tungsten with a valence lower than 6 , formed at the cathode, and eventually the whole solution became colored. It is thought that the inclusion of partially reduced tungsten compounds might be the cause of the oxide content of the deposits and their poor physical characteristics. Attempts were made to keep the bath free of tungsten blue by bubbling air around the cathode, or by the judicious additions of hydrogen peroxide, but the deposits were not improved.

\section{Deposition of!Alloys From Acid Solutions}

Because of the lack of success with acid plating solutions, attention was directed to the alkaline baths. Holt showed that the deposit that C. G. Fink had obtained from the electrolysis of an alkaline tungstate solution was not pure tungsten, but an alloy containing iron $[13,15]$, and that alloys of tungsten with other metals could be obtained from carbonate solutions $[16,20]$. These solutions, however, yielded only a small quantity of deposit before they ceased to plate and hence were not suitable for commercial application. Several Russian workers obtained nickel-tungsten alloys $[9,14,22]$ from ammoniacal solutions. When their work was repeated, this process was found to be more practicable than Holt's. A paper by Vaaler and Holt [25] on the electrodeposition of nickel-tungsten alloys from ammoniacal citrate solutions appeared while this report was in preparation. As the process described in their paper is similar to the one developed here, it will be discussed in more detail under the deposition on nickel-tungsten alloys.

\section{Experimental Methods}

No special plating technics were used in this investigation. The plating baths varied in size from small beakers for the initial trials to 6-liter Pyrex cylinders for baths used in the plating of specimens for the study of properties. The largest bath contained about 15 liters. External heating along with thermoregulators controlled the temperature to about $\pm 3 \mathrm{deg} \mathrm{C}$, and the solution was kept at a constant level by a float valve.

In the initial experiments, which were made on a beaker scale, for determining the composition of deposits as a function of the bath composition and plating conditions, a cylindrical gold rod about $5 \mathrm{~mm}$ in diameter was used as cathode. The cur- rent density on a rod is more uniform than on a flat sheet. The color of the gold made it easy to observe whether plating had occurred. The alloy deposits could readily be dissolved from the gold, without attacking the latter, by pouring a mixture of nitric and hydrofluoric acids over the gold rod, placed in a platinum test tube.

Thick deposits were required for the measurement of physical properties. These deposits were made on copper tubing that had an outside diameter of $5 \mathrm{~mm}$ and a wall thickness of $0.25 \mathrm{~mm}$. The end of the tube was closed with a plug to prevent contamination of the solution with copper, and a length of from 15 to $30 \mathrm{~cm}$ was plated in a 6-liter Pyrex cylinder. Separation of the deposit from the copper was effected by removing the latter chemically by the action of sodium polysulfide (approximately $M \mathrm{Na}_{2} \mathrm{~S}_{2}$ ), followed by immersion in a solution of sodium cyanide (about $100 \mathrm{~g} /$ /iter), which served to loosen and dissolve the copper sulfide formed by the polysulfide treatment. The treatments with the polysulfide and cyanide were alternated at intervals of from 15 minutes to 1 hour.

This procedure for stripping the copper away from the alloy deposit constituted the first test of soundness of the alloy. Sound deposits came through the stripping operation intact, whereas others, particulary those that had been deposited at high current densities or from certain unsatisfactory baths, crumbled.

\section{Electrodeposition of Alloys}

\section{General Considerations}

The results of the investigation on deposition are discussed in three sections: alloys of cobalttungsten; nickel-tungsten; and iron tungsten. Although the methods of plating are similar, the differences are sufficiently great, especially in the case of the iron alloys, to require separate descriptions. The physical properties of all three alloys will be discussed in connection with each property. The investigation of the cobalt-tungsten alloys has been the most thorough, and that of the iron alloys the least. The work with the latter was made more difficult by the two states of oxidation of iron, and much work needs to be done on these alloys. From our experience, a successful plating solution for codepositing tungsten with a metal of the iron group requires, in 
addition to compounds containing the two metals, a salt of certain hydroxy-organic acids, ammonium compounds, and an excess of $\mathrm{NH}_{4} \mathrm{OH}$ to bring the $\mathrm{pH}$ to 8.0 or above. Of the hydroxy acids investigated, those aliphatic hydroxycarboxylic acids in which the sum of the hydroxy and carboxyl groups is greater than three operate the best. One exception to this rule is hydroxyacetic acid, which contains only one hydroxyl and one carboxyl group, but yields fairly satisfactory baths. A practical requirement is that the salts of the acid be quite soluble, otherwise a bath of satisfactory metal content cannot be obtained. Among the satisfactory acids may be mentioned tartaric, malic, gluconic, saccharic, citric and hydroxyacetic. On the other hand, salts of organic acids such as lactic, acetic, oxalic, and salicylic, and of inorganic acids, were not satisfactory. Mucic acid was of limited value because of the low solubility of its salts. Some of the amino-acids were almost usable. Glutamic acid and glycine yielded fairly satisfactory deposits, which, however, were not quite equal in soundness to those from the hydroxy acids. Of the hydroxy acids commercially available, hydroxyacetic acid is one of the cheapest, costing only about onefifth as much as tartaric acid.

It is not possible to make general statements regarding the concentrations of each constituent of the bath, because the solubility of one substance is affected by the presence of the other constituents. Deposits have been obtained from solutions that range in composition from 100 $\mathrm{g} /$ liter of the iron group metal and $25 \mathrm{~g} /$ liter of tungsten, to $10 \mathrm{~g}$ /liter of the iron group metal and $150 \mathrm{~g} /$ liter of tungsten. The salts of the organic acids have been used in concentrations as high as $600 \mathrm{~g}$ /liter and the ammonium salts as high as $300 \mathrm{~g} /$ liter.

Most of the plating was done above $90^{\circ} \mathrm{C}$ and at a $\mathrm{pH}$ above 8.5. The cathode current density varied from 1 to $30 \mathrm{amp} / \mathrm{dm}^{2}$.

\section{Electrodeposition of Cobalt-Tungsten Alloys}

Introduction.-The main commercial interest in the cobalt-tungsten alloys stems from their hardness [23]. They are related to stellite, an alloy of cobalt and chromium with tungsten or molybdenum, except that they contain no chromium. Attempts made in this investigation to electrodeposit a ternary alloy containing an appre- ciable amount of chromium have not been successful. The hot-hardness of alloys such as stellite makes them useful for high-speed tools and for engineering applications where good strength or hardness at elevated temperatures is required. At temperatures below $700^{\circ} \mathrm{C}$, high-speed toolsteels may have a greater hardness than stellite, but at higher temperatures, the hardness of toolsteel rapidly decreases, and the stellite is superior. As will be shown in the discussion of properties, the cobalt-tungsten alloys have a hot-hardness approaching that of stellite.

Planting Solutions. Preparation and Solubility Relations.-The plating solution that was considered most satisfactory for the electrodeposition of cobalt-tungsten alloys had the following composition:

$\begin{array}{lr}\text { Cobalt (as chloride or sulfate) } & \text { g/liter } \\ \text { Tungsten (as sodium tungstate) } & 25 \\ \text { Rochelle salt } & 25 \\ \text { Ammonium chloride or sulfate } \ldots \ldots & 50 \\ \text { Ammonium hydroxide to a pH of } 8.5 \ldots \ldots\end{array}$

The operating conditions were temperature, $90^{\circ} \mathrm{C}$ or above; $\mathrm{pH}, 8.5$ or above; current density, 2 to 5 amp $/ \mathrm{dm}^{2}$. Although the concentrations given are preferable, they are not in any way critical. The concentration of tungsten may vary from zero to saturation, depending on the composition of de-posit desired. In the absence of tungsten, the bath gives a cobalt deposit that is rather dark in color, and for depositing cobalt, this bath has no advantage over an ordinary cobalt bath of low $\mathrm{pH}$. As tungsten is added, the deposits become brighter. The concentration of the cobalt in the bath may vary from $0.5 \mathrm{~g} /$ /iter to saturation, and that of Rochelle salt over wide limits. If either the ammonium salt or the Rochelle salt is entirely omitted, the behavior of the bath is considerably different, as will be discussed later.

There is an advantage in employing plating solutions that are high in metal content, because higher current densities can be used and thicker smooth deposits can be obtained. For this reason most attention was given to concentrated baths. Solutions saturated with salts, however, are not satisfactory, because the deposits are more likely to be pitted.

It was found that when strong solutions of the above types were kept at the temperature of operation (usually $90^{\circ}$ to $100^{\circ} \mathrm{C}$ ), precipitates formed and the bath composition was altered. To avoid 
the study of unstable baths, solutions of varying composition were sealed in bottles and allowed to stand on a steam bath for about a week, so that they would come to chemical equilibrium, and were then analyzed. In this way some solutions that initially seemed capable of holding in solution high concentrations of metals were found to be unstable. Although the principle of the solubility product is not strictly applicable to these strong solutions, it was found that the product of the concentrations of cobalt and of tungsten (in $\mathrm{g} /$ liter) was fairly constant, when the concentrations of the other constituents were fixed. This relation made it possible to indicate the approximate maximum concentrations of cobalt and tungsten that could be used in a given solution. Some data illustrating the application of the solubility principle are given in table 1 , part $\mathrm{A}$.

TABLE 1.-Solubility relations of cobalt and tungsten in ammoniacal solutions of $\mathrm{pH} 8.5$

A. Application of the solubility product principle (each solution contained ammonium chloride, $50 \mathrm{~g} / \mathrm{liter}$ )

\begin{tabular}{|c|c|c|c|c|c|c|c|c|c|c|c|c|}
\hline \multirow{4}{*}{ No. } & \multicolumn{3}{|c|}{ Salt of organic acid } & \multicolumn{9}{|c|}{ Metal concentration } \\
\hline & \multirow{3}{*}{ Type } & \multicolumn{2}{|c|}{ Concentration } & \multicolumn{4}{|c|}{ Initial } & \multicolumn{4}{|c|}{ Final } & \multirow{3}{*}{$\begin{array}{l}\text { Solubil- } \\
\text { ity } \\
\text { product, } \\
\text { Co } \times W \\
\text { g/liter }\end{array}$} \\
\hline & & & & \multicolumn{2}{|c|}{$\mathrm{Co}$} & \multicolumn{2}{|c|}{ W } & \multicolumn{2}{|c|}{ Co } & \multicolumn{2}{|c|}{ W } & \\
\hline & & Molarity & $\mathrm{g} /$ liter & Molarity & g/liter & Molarity & $\mathrm{g} /$ liter & Molarity & $\mathrm{g} /$ liter & Molarity & g/liter & \\
\hline 1 & Sodium hydroxyacetate & 2. 6 & 260 & 0.85 & 50 & 0.13 & 25 & 0.64 & 38 & 0.02 & 4 & 152 \\
\hline 2 & do & 2. 6 & 260 & .85 & 50 & .27 & 50 & .47 & 28 & .03 & 6 & 168 \\
\hline 3 & do $d 0$ & 2. 6 & 260 & .85 & 50 & .54 & 100 & .14 & 8 & .11 & 20 & 160 \\
\hline 4 & Ammonium hydroxyacetate ..... & 2. 6 & 245 & .85 & 50 & .13 & 25 & .78 & 46 & .04 & 8 & 368 \\
\hline 5 & . do & 2. 6 & 245 & .85 & 50 & .27 & 50 & .54 & 32 & .08 & 14 & 448 \\
\hline 6 & do 0 - & 2. 6 & 245 & .85 & 50 & .54 & 100 & .25 & 15 & .12 & 22 & 330 \\
\hline 7 & Potassium malate & 2. 2 & 470 & .85 & 50 & .27 & 50 & .54 & 32 & .18 & 33 & 1,056 \\
\hline 8 & _ do & 2. 2 & 470 & .85 & 50 & .54 & 100 & .40 & 23 & .28 & 52 & 1,196 \\
\hline 9 & Rochelle salt & 1.4 & 400 & .85 & 50 & .27 & 50 & 1.0 & 58 & .29 & 53 & 3,074 \\
\hline 10 & _. do & 1. 4 & 400 & .42 & 25 & .54 & 100 & 0.54 & 32 & .40 & 72 & 2,304 \\
\hline
\end{tabular}

B. Effect of concentrations of salts of organic acids and of ammonium salts on the solubility product

\begin{tabular}{|c|c|c|c|c|c|c|}
\hline & \multicolumn{3}{|c|}{ Salt } & \multicolumn{2}{|c|}{$\mathrm{NH}_{4} \mathrm{Cl}$} & \multirow{3}{*}{$\begin{array}{l}\text { Solubil- } \\
\text { ity } \\
\text { product, } \\
\text { Co } \times W \\
\text { (g/liter) }\end{array}$} \\
\hline & \multirow{2}{*}{ Type } & \multicolumn{2}{|c|}{ Concentration } & \multirow{2}{*}{ Molarity } & \multirow{2}{*}{ g/liter } & \\
\hline & & Molarity & $\mathrm{g} /$ liter & & & \\
\hline 11 & Rochelle salt_..... & 1.4 & 400 & 1.0 & 50 & 2,700 \\
\hline 12 & - do $0_{-}$ & 2.1 & 600 & 1.0 & 50 & 2,300 \\
\hline 13 & do & .7 & 200 & 1. 0 & 50 & 500 \\
\hline 14 & Ammonium tartrate & 1.3 & 245 & 1.0 & 50 & 2.000 \\
\hline 15 & Sodium hydroxyacetate & 2.6 & 260 & 1.0 & 50 & 160 \\
\hline 16 & - $\mathrm{d} 0$ & 2.6 & 260 & 4.0 & 200 & 250 \\
\hline 17 & - do do & 5.2 & 520 & $\ldots$ & $-\ldots$ & 85 \\
\hline 18 & -10_do & 5.2 & 520 & 1.0 & 50 & 540 \\
\hline 19 & Ammonium hydroxyacetate & 2. 6 & 245 & 1.0 & 50 & 380 \\
\hline 20 & [.._do do & 2.6 & 245 & 4.0 & 200 & 510 \\
\hline 21 & - & 5. 2 & 490 & 1.0 & 50 & 4,000 \\
\hline 22 & Potassium malate & 2.2 & 470 & 1.0 & 50 & 1,130 \\
\hline 23 & Ammonium malate & 2. 2 & 376 & 1.0 & 50 & 1,250 \\
\hline 24 & Ammonium sulfate & 2.3 & 300 & $\ldots$ & & ....... \\
\hline 25 & Ammonium sulfamate & 2.0 & 230 & ...... & $\cdots$ & (1) \\
\hline 26 & Ammonium fluoborate & 1.9 & 200 & ........... & ..... & $(1)$ \\
\hline 27 & Ammonium bifluoride & 3.5 & 200 & .... & -..- & (1) \\
\hline 28 & Sodium hexametaphosphate & .3 & 200 & ..... & & (1) \\
\hline 29 & Ammonium acid phosphite & 1.2 & 120 & & & (1) \\
\hline
\end{tabular}

1 Less than 75 . 
TABLE 2.-Composition of cobalt-t ungsten alloys

(In addition to the constituents listed below, each solution contained ammonium chloride, $50 \mathrm{~g} /$ liter, unless otherwise stated, and was operated at $90^{\circ} \mathrm{O}$ at a $\mathrm{pH}$ of 8.5.

\begin{tabular}{|c|c|c|c|c|c|c|c|c|c|c|c|c|}
\hline \multirow{4}{*}{ No. } & \multirow{4}{*}{$\begin{array}{c}\text { W/Co } \\
\text { (weight) }\end{array}$} & \multicolumn{7}{|c|}{ Bath composition } & \multicolumn{2}{|c|}{ Cathode efficiency- } & \multicolumn{2}{|c|}{ Tungsten in deposit- } \\
\hline & & \multicolumn{2}{|c|}{ Co } & \multicolumn{2}{|c|}{ W } & \multicolumn{3}{|c|}{ Organic salt } & \multirow{3}{*}{$2 \mathrm{amp} / \mathrm{dm}^{2}$} & \multirow{3}{*}{$5 \mathrm{amp} / \mathrm{dm}^{2}$} & \multirow{3}{*}{$2 \mathrm{amp} / \mathrm{dm}^{2}$} & \multirow{3}{*}{$5 \mathrm{amp} / \mathrm{dm}^{2}$} \\
\hline & & \multirow{2}{*}{ Molarity } & \multirow{2}{*}{ g/liter } & \multirow{2}{*}{ Molarity } & \multirow{2}{*}{$\mathrm{g} /$ liter } & \multirow{2}{*}{ Type } & \multicolumn{2}{|c|}{ Concentration } & & & & \\
\hline & & & & & & & Molarity & g/liter & & & & \\
\hline
\end{tabular}

TARTRATE

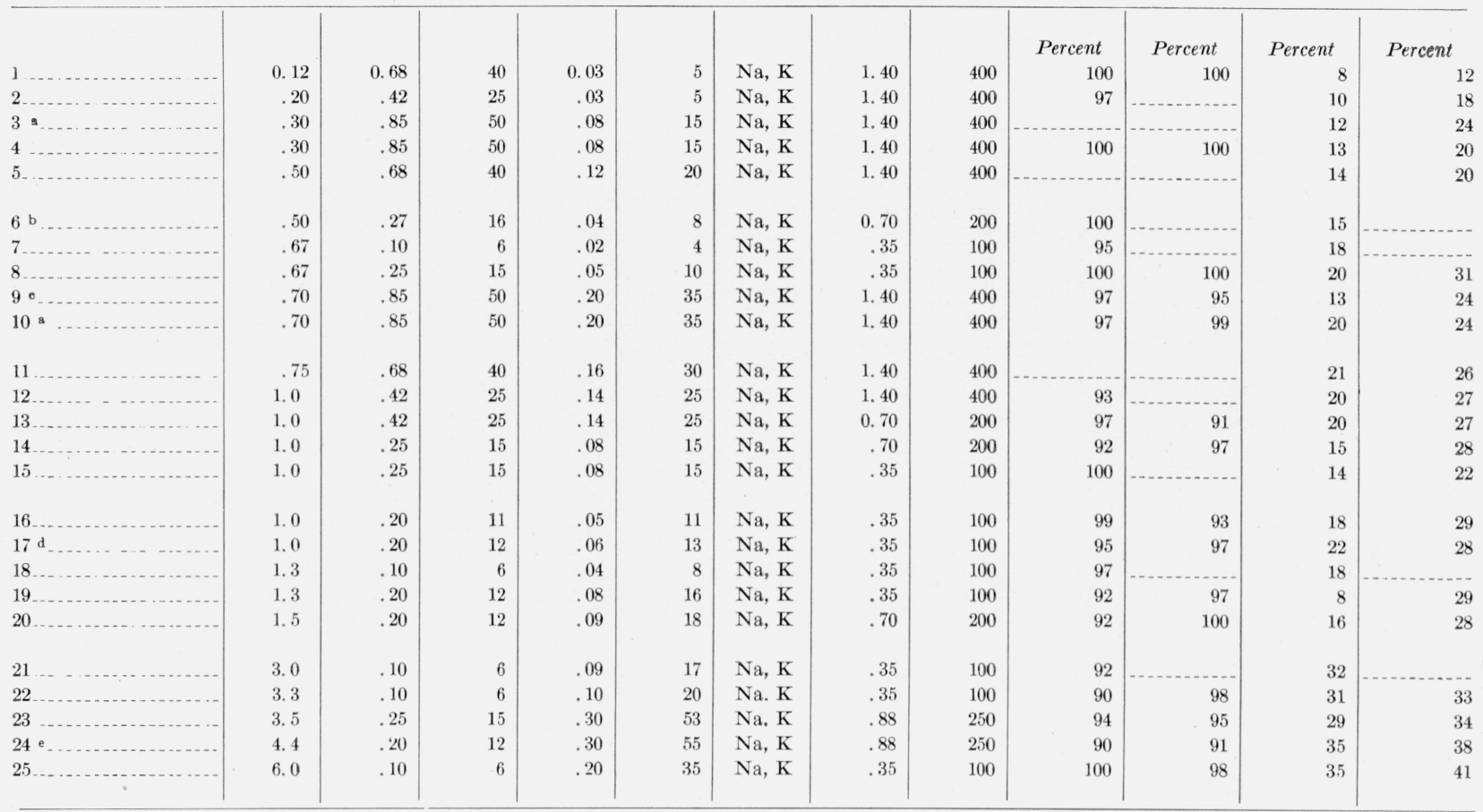

CITRATE

\begin{tabular}{|c|c|c|c|c|c|c|c|c|c|c|c|c|}
\hline 26 & 0.14 & 0.60 & 35 & 0.03 & 5 & $\mathrm{Na}$ & 0.60 & 200 & 87 & 70 & 23 & 27 \\
\hline $27 \ldots \ldots+1$ & .14 & .60 & 35 & .03 & 5 & $\mathrm{NH}_{4}$ & 1. 20 & 300 & 83 & 78 & 23 & 22 \\
\hline $28 \mathrm{f} \ldots \ldots$ & .14 & .60 & 35 & .03 & 5 & $\mathrm{NH}_{4}$ & 1. 20 & 300 & 79 & 77 & 23 & 24 \\
\hline 29 & .50 & .42 & 25 & .07 & 13 & $\mathrm{Na}$ & 0.60 & 200 & 66 & 59 & 30 & 42 \\
\hline $39 \ldots \ldots \ldots$ & 1. 0 & .42 & 25 & .14 & 25 & $\mathrm{Na}$ & .60 & 200 & 78 & 71 & 41 & 39 \\
\hline $31 \ldots \ldots$ & 6.0 & .10 & 6 & .20 & 35 & $\mathrm{Na}$ & .60 & 200 & s 26 & & g 42 & \\
\hline $32 \ldots \ldots$ & 6.0 & .20 & 12 & .38 & 70 & $\mathrm{Na}$ & .60 & 200 & g 27 & & g 42 & \\
\hline $33 \ldots$ & 12.0 & .10 & 6 & .38 & 70 & $\mathrm{Na}$ & .30 & 100 & g 26 & & 850 & \\
\hline 34 & 35.0 & .02 & 1 & .20 & 35 & $\mathrm{Na}$ & .30 & 100 & g 31 & . & g 57 & \\
\hline
\end{tabular}

MALATE

\begin{tabular}{|c|c|c|c|c|c|c|c|c|c|c|c|c|}
\hline 35 & 0.50 & 0.85 & 50 & 0.14 & 25 & K & 1.5 & 310 & 89 & 85 & 11 & 12 \\
\hline 36 & .67 & .25 & 15 & .06 & 10 & $\mathrm{NH}_{4}$ & 0.7 & 125 & 91 & 95 & 17 & 27 \\
\hline 37 & 1.0 & .85 & 50 & 26 & 50 & $\mathrm{~K}$ & 1.5 & 310 & 68 & 76 & 10 & 15 \\
\hline $38 \ldots \ldots \ldots-2 \ldots$ & 2.0 & .85 & 50 & .54 & 100 & $\mathrm{NH}_{4}$ & 1.5 & 250 & 85 & 93 & 24 & 27 \\
\hline 39 & 4. 0 & .42 & 25 & .54 & 100 & $\mathrm{~K}$ & 1.5 & 310 & 100 & 100 & 24 & 26 \\
\hline
\end{tabular}

See footnotes at end of table. 
TABLE 2.-Composition of cobalt-tungsten alloys-Continued

\begin{tabular}{|c|c|c|c|c|c|c|c|c|c|c|c|c|}
\hline \multirow{4}{*}{ No. } & \multirow{4}{*}{$\begin{array}{c}\text { W/Co } \\
\text { (weight) }\end{array}$} & \multicolumn{7}{|c|}{ Bath composition } & \multicolumn{2}{|c|}{ Cathode efficiency- } & \multicolumn{2}{|c|}{ Tungsten in deposit- } \\
\hline & & \multicolumn{2}{|c|}{$\mathrm{Co}$} & \multicolumn{2}{|c|}{ W } & \multicolumn{3}{|c|}{ Organic salt } & \multirow{3}{*}{$2 \mathrm{amp} / \mathrm{dm}^{2}$} & \multirow{3}{*}{$5 \mathrm{amp} / \mathrm{dm}^{2}$} & \multirow{3}{*}{$2 \mathrm{amp} / \mathrm{dm}^{2}$} & \multirow{3}{*}{$5 \mathrm{amp} / \mathrm{dm}^{2}$} \\
\hline & & \multirow{2}{*}{ Molarity } & \multirow{2}{*}{$\mathrm{g} /$ liter } & \multirow{2}{*}{ Molarity } & \multirow{2}{*}{$\mathrm{g} /$ liter } & \multirow{2}{*}{ Type } & \multicolumn{2}{|c|}{ Concentration } & & & & \\
\hline & & & & & & & Molarity & $\mathrm{g} / \mathrm{liter}$ & & & & \\
\hline
\end{tabular}

HYDROXYACETATE

\begin{tabular}{|c|c|c|c|c|c|c|c|c|c|c|c|}
\hline 40 & 0.15 & 1.7 & 100 & 0.08 & 15 & $\mathrm{Na}$ & 5.0 & 500 & & - & 4 \\
\hline $41 \ldots$ & .25 & 1.7 & 100 & .14 & 25 & $\mathrm{NH}_{4}$ & 5.0 & 500 & & 8 & 12 \\
\hline $42 \ldots$ & .30 & 0.85 & 50 & .08 & 15 & $\mathrm{Na}$ & 5.0 & 500 & - & 6 & 7 \\
\hline 43 & 2.0 & .42 & 25 & .26 & 50 & $\mathrm{NH}_{4}$ & 5.0 & 500 & 96 & 21 & 25 \\
\hline
\end{tabular}

GLUCONATE

\begin{tabular}{|c|c|c|c|c|c|c|c|c|c|c|c|c|}
\hline 44 & 0.90 & 0.34 & 20 & 0.10 & 17 & $\mathrm{NH}_{4}$ & 0.50 & 100 & g 90 & 94 & g 5 & 10 \\
\hline $45 \ldots \ldots$ & .90 & .68 & 40 & .20 & 35 & $\mathrm{NH}_{4}$ & .50 & 100 & g 93 & 95 & s 3 & 5 \\
\hline $46 \ldots$ & 1.8 & .34 & 20 & .20 & 35 & $\mathrm{NH}_{4}$ & .50 & 100 & g 98 & 98 & g 8 & 21 \\
\hline $47 \ldots \ldots$ & 1.8 & .68 & 40 & .40 & 70 & $\mathrm{NH}_{4}$ & .50 & 100 & 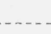 & 94 & . & 15 \\
\hline 48 & 6.0 & .10 & 6 & .20 & 35 & $\mathrm{NH}_{4}$ & .50 & 100 & b 97 & 95 & h 33 & 35 \\
\hline
\end{tabular}

GLUTAMATE

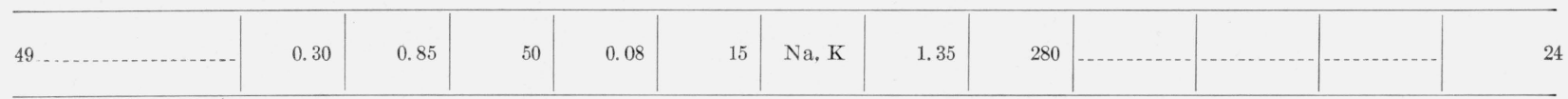

\section{LACTATE}

\begin{tabular}{l|r|r|r|r|r|r|r|r|r}
\hline $50 \ldots \ldots$ & 3.0 & 0.08 & 5 & 0.08 & 15 & $\mathrm{~K}$ & 4.5 & 570 & 90 \\
\hline
\end{tabular}

ACETATE

\begin{tabular}{l|r|r|r|r|r|r|r|r|r|r}
\hline $51 \ldots \ldots$ & 1.0 & 0.20 & 12 & 0.08 & 15 & $\mathrm{Na}$ & 3.0 & 400 & \\
\hline
\end{tabular}

INORGANIC

\begin{tabular}{l|l|r|r|r|r|r|r|r|r}
\hline $52 \mathrm{i} \ldots \ldots$ & 0.5 & 0.39 & 23 & 0.07 & 12 & & & & \\
\end{tabular}

a Bath contains $\mathrm{NH}_{4} \mathrm{Cl}, 200 \mathrm{~g} /$ liter.

b Bath contains $\mathrm{NH}_{4} \mathrm{Cl}, 100 \mathrm{~g} /$ liter.

3 Bath contains no $\mathrm{NH}_{4} \mathrm{Cl}$.

d Bath contains $\mathrm{NH}_{4} \mathrm{Cl}, 300 \mathrm{~g} /$ liter.

e Bath contains $\mathrm{NH}_{4} \mathrm{Cl}, 150$ g/liter.

The manner in which the solubility of cobalt and tungsten are affected by the concentrations of the other constituents of the solution is shown in table 1 , part B. The values of the solubility product given here are rough guides to the variations in solubility of the metals with a change in composition of the plating solutions. In applying the solubility product principle to the preparation of a given solution, the maximum solubility of the individual metals must not be exceeded. For practical purposes, the upper limit of cobalt is f Bath contains $\left(\mathrm{NH}_{4}\right)_{2} \mathrm{SO}_{4}, 200 \mathrm{~g}$ /liter.

g $3 \mathrm{amp} / \mathrm{dm}^{2}$.

h $31 / 2 \mathrm{amp} / \mathrm{dm}^{2}$.

i Bath contains $\left(\mathrm{NH}_{4}\right)_{2} \mathrm{SO}_{4}, 300 \mathrm{~g} /$ liter.

about $50 \mathrm{~g} /$ liter (although concentrations of 100 $\mathrm{g}$ /liter have been attained), and the upper limit of tungsten is about $150 \mathrm{~g} /$ liter (although a concentration of $200 \mathrm{~g}$ /liter has been attained).

The data in table 1, part B, show that a high concentration of the organic acid permits high concentrations of cobalt and tungsten, which are much less soluble in the absence of the organic salts. The tartrate solution has the best solubility for cobalt and tungsten. The use of ammonium salts of organic acids instead of sodium salts 
lowers the solubility product in the tartrate solution, increases it considerably in the hydroxyacetate solution, and has little effect in the malate solution.

The solubility of tungstates in ammoniacal solutions in the absence of cobalt is interesting. In an ammoniacal solution containing no ammonium salts, sodium tungstate $\left(\mathrm{Na}_{2} \mathrm{WO}_{4} \cdot 2 \mathrm{H}_{2} \mathrm{O}\right)$ will dissolve to the extent of $600 \mathrm{~g} /$ liter (equivalent to $300 \mathrm{~g}$ of tungsten). If a strong solution of sodium tungstate is added to a strong solution of ammonium sulfate, a precipitate forms that will not redissolve entirely on heating. However, if the sodium tungstate solution is made ammoniacal before it is added to the ammonium salt solution, a stable solution results, which can hold $200 \mathrm{~g}$ of sodium tungstate per liter in the presence of $300 \mathrm{~g}$ of ammonium sulfate per liter. The salts of the hydroxy acids do not seem to affect appreciably the solubility of tungstates. A solution similar to the plating solutions, for example, containing
$400 \mathrm{~g}$ of Rochelle salt per liter and $100 \mathrm{~g}$ of ammonium sulfate per liter will dissolve $400 \mathrm{~g}$ of sodium tungstate per liter.

Factors affecting the composition of deposits.Deposits containing up to 50 percent of tungsten have been obtained, but the deposits that are sound enough for engineering applications do not contain over 35 percent of tungsten. The most influential factors on the composition of the deposit were: the metal ratio in the solution $(\mathrm{W} / \mathrm{Co})$; the type of organic hydroxy acid used; and the current density. Other variables, such as the concentration of the solution, $\mathrm{pH}$, and temperature, had only a minor effect on the composition of the deposit; but in some cases had a large effect on its physical properties.

The effects of variations in composition of the plating solution on the composition of the deposit are illustrated in table 2 , the effects of current density in table 3 , and the effects of temperature in table 4.

TABLE 3.-Effect of current density on composition of cobalt-tungsten alloys

(Each solution contained ammonium chloride, $50 \mathrm{~g} /$ liter. Temperature, $90^{\circ} \mathrm{C}, \mathrm{pH} 8.5$.)

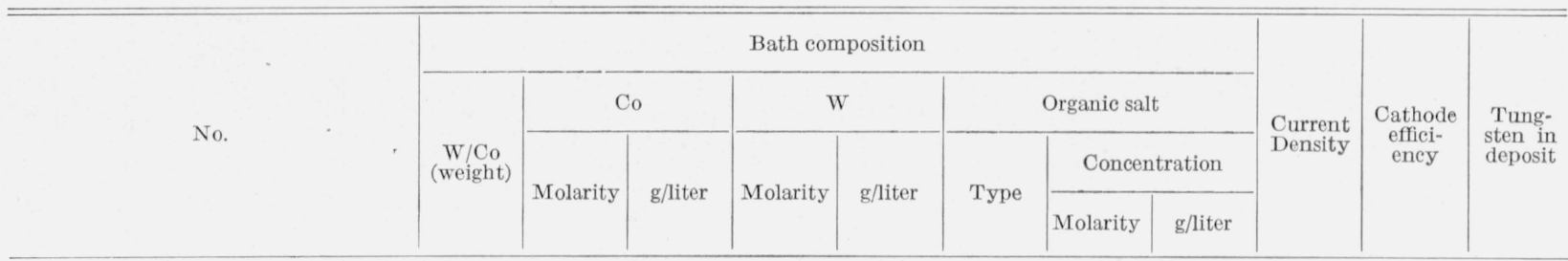

TARTRATE

\begin{tabular}{|c|c|c|c|c|c|c|c|c|c|c|c|}
\hline & & & & & & & & & $a m p / d m^{2}$ & Percent & Percent \\
\hline $1 \ldots \ldots$ & 0.13 & 0.68 & 40 & 0.03 & 5 & $\mathrm{Na}, \mathrm{K}$ & 1.4 & 400 & 1 & 100 & 4 \\
\hline $2 \ldots \ldots \ldots$ & .13 & .68 & 40 & .03 & 5 & $\mathrm{Na}, \mathrm{K}$ & 1.4 & 400 & 2 & 100 & 8 \\
\hline $3 \ldots$ & .13 & .68 & 40 & .03 & 5 & $\mathrm{Na}, \mathrm{K}$ & 1.4 & 400 & 3 & 100 & 10 \\
\hline 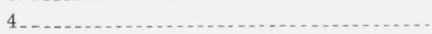 & .13 & .68 & 40 & .03 & 5 & $\mathrm{Na}, \mathrm{K}$ & 1.4 & 400 & 5 & 100 & 12 \\
\hline $5 \ldots \ldots$ & .30 & .85 & 50 & .09 & 15 & $\mathrm{Na}, \mathrm{K}$ & 1.4 & 400 & 1 & 100 & 9 \\
\hline $6 \ldots$ & .30 & .85 & 50 & .09 & 15 & $\mathrm{Na}, \mathrm{K}$ & 1.4 & 400 & 2 & & 12 \\
\hline 7 & .30 & .85 & 50 & .09 & 15 & $\mathrm{Na}, \mathrm{K}$ & 1.4 & 400 & 3 & 2.... & 16 \\
\hline 8 & .30 & .85 & 50 & .09 & 15 & $\mathrm{Na}, \mathrm{K}$ & 1.4 & 400 & 5 & $\ldots$ & 19 \\
\hline 9 & .30 & .85 & 50 & .09 & 15 & $\mathrm{Na}, \mathrm{K}$ & 1.4 & 400 & 10 & & 26 \\
\hline $10 \ldots \ldots$ & 1.0 & .42 & 25 & .13 & 25 & $\mathrm{Na}, \mathrm{K}$ & 0.70 & 200 & 1 & 88 & 9 \\
\hline $11 \ldots \ldots$ & 1.0 & .42 & 25 & .13 & 25 & $\mathrm{Na}, \mathrm{K}$ & .70 & 200 & 2 & 87 & 21 \\
\hline 12 & 1.0 & .42 & 25 & .13 & 25 & $\mathrm{Na}, \mathrm{K}$ & .70 & 200 & 5 & 91 & 25 \\
\hline $13_{2}$ & 1.0 & .42 & 25 & .13 & 25 & $\mathrm{Na}, \mathrm{K}$ & .70 & 200 & 10 & 82 & 31 \\
\hline 14 & 1.0 & .25 & 15 & .09 & 15 & $\mathrm{Na}, \mathrm{K}$ & .35 & 100 & 1 & 100 & 14 \\
\hline 15 & 1.0 & .25 & 15 & .09 & 15 & $\mathrm{Na}, \mathrm{K}$ & .35 & 100 & 2 & 100 & 18 \\
\hline 16 & 1.0 & .25 & 15 & .09 & 15 & $\mathrm{Na}, \mathrm{K}$ & .35 & 100 & 5 & 100 & 24 \\
\hline 17 & 6.0 & .08 & 6 & .20 & 35 & $\mathrm{Na}, \mathrm{K}$ & .35 & 100 & 1 & 95 & 14 \\
\hline 18 & 6.0 & .08 & 6 & $.2 \theta$ & 35 & $\mathrm{Na}, \mathrm{K}$ & .35 & 100 & 2 & $-\ldots$ & 35 \\
\hline 19 & 6.0 & .08 & 6 & .20 & 35 & $\mathrm{Na}, \mathrm{K}$ & .35 & 100 & 3 & 98 & 33 \\
\hline 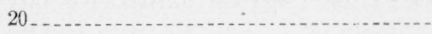 & 6.0 & .08 & 6 & .20 & 35 & $\mathrm{Na}, \mathrm{K}$ & .35 & 100 & 5 & 98 & 41 \\
\hline
\end{tabular}


TABLE 3.-Effect of current density on composition of cocalt-tungsten alloys-Continued

(Each solution contained ammonium chloride, $50 \mathrm{~g} /$ liter. Temperature, $90^{\circ} \mathrm{C}, \mathrm{pH} 8.5$.)

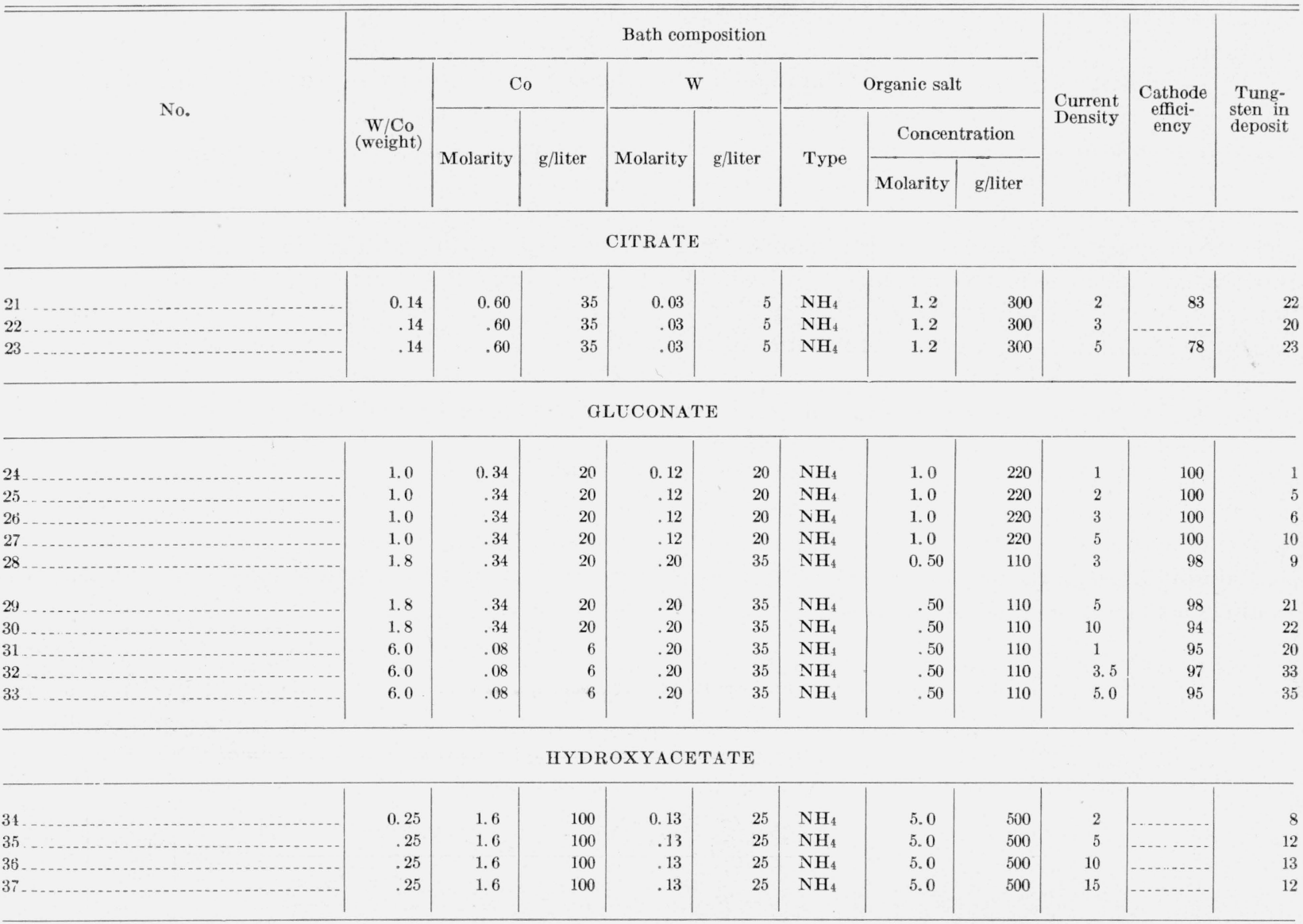

TABLE 4.-Effects of bath temperature on composition of cobalt-tungsten alloys

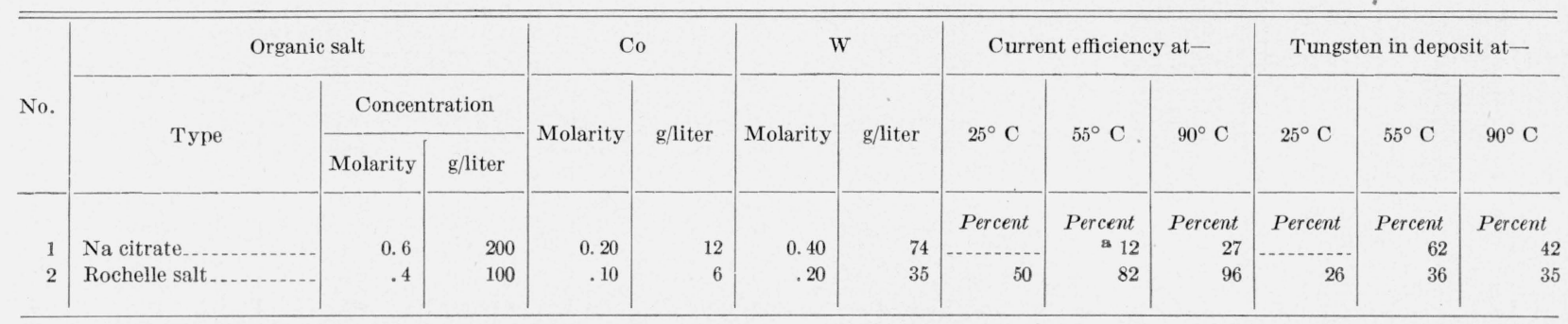

a Bath operated at $45^{\circ} \mathrm{C}$ instead of $55^{\circ} \mathrm{C}$.

The main conclusions derived from these data are as follows:

Metal-ratio.-The tungsten-cobalt ratio of the bath is the most important factor affecting the composition of the deposit. As this ratio increases, the percentage of tungsten in the deposit also increases, but the increase is slight when the solution contains more than three times as much tungsten as cobalt. (See figs. 1 and 3 ). The deposit does not contain more than about 50 percent of tungsten, even if the tungsten-cobalt ratio in the solution is as high as 35 .

The citrate solution with a low ratio of tungsten to cobalt (solution containing cobalt $35 \mathrm{~g}$ /liter and tungsten $5 \mathrm{~g} /$ liter, No. 21, table 3) deserves special consideration because the tungsten-cobalt ratio of the deposit (0.3) is higher than in the solution (0.14). This situation indicates that 
tungsten has reversed its role and is the more readily deposited metal. At any rate, in the citrate solution, cobalt and tungsten must have deposition potentials that are close together, otherwise it would be difficult to explain why there is so little variation in the composition of the deposit with current density.

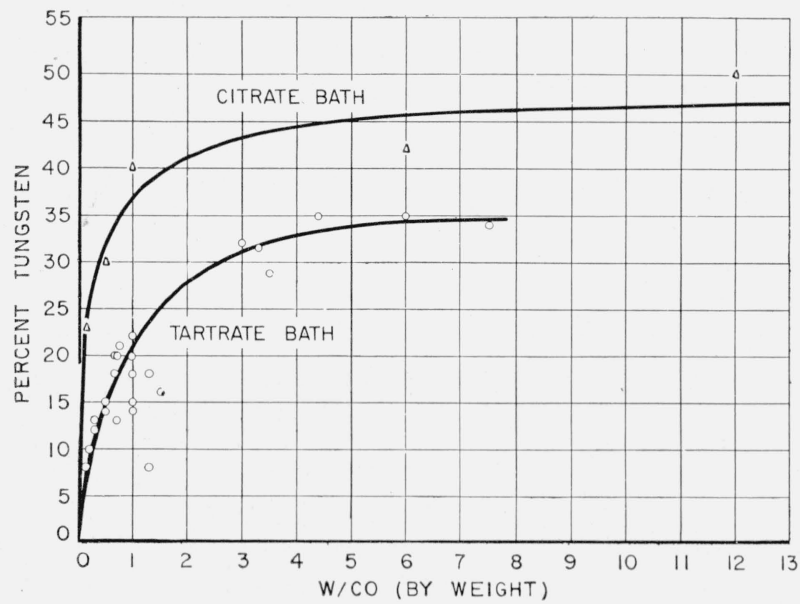

Figure 1.-Effect of tungsten-cobalt ratio on the percentage of tungsten in the deposit from tartrate and citrate alloy baths of various compositions.

The current density is $2 \mathrm{amp} / \mathrm{dm}^{2}$.

Current density. - The content of tungsten in the deposit increases with the current density (table 3 ). This is to be expected, as under most conditions tungsten behaves as the less noble of the two metals. In the citrate solution at low current densities a relatively higher proportion of tungsten is obtained in the deposit than in other baths, and in this particular case an increase in the current density does not significantly increase the tungsten content of the deposit.

Temperature.-The composition of the deposit does not vary significantly with temperature (table 4), but the cathode efficiency improves considerably as the temperature is raised. ${ }^{2}$ The main objection to deposits obtained at low temperatures is that their physical properties are inferior to those obtained above $90^{\circ} \mathrm{C}$, as they are dark in color and unsound. On stripping the base metal away from them, they showed the presence of many cracks and usually fell to pieces. Table 17 shows that such deposits have more oxide inclusions than the deposits obtained at $90^{\circ} \mathrm{C}$. Because

${ }^{2}$ It is possible to compute the approximate cathode efficiency for most of these deposits without knowledge of their exact composition because the equivalent weights of $\mathrm{WVI}, \mathrm{Co}^{\mathrm{II}}, \mathrm{NiII}$, and $\mathrm{Fe}^{\mathrm{II}}$ are nearly the same. of these disadvantages, most of the tungsten alloys were deposited from hot solutions.

Type of Organic Acid. - The organic acids vary in their capacity to bring about codeposition of tungsten. The following summary shows that gluconic acid yields deposits with the lowest tungsten content and citric acid the highest.

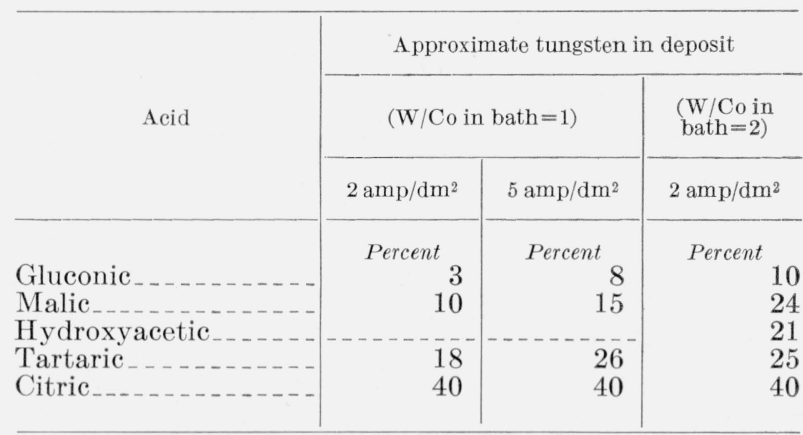

Concentration of Organic Salts.- Not enough data are at hand to determine accurately the effect of the concentration of the organic salt on the composition of the deposit. The effect seems to be small in the tartrate bath (see experiments 12 and $13 ; 14$ and 15 ; table 2 ).

Total Concentration of Cobalt and Tungsten.The content of tungsten in the deposit should increase as the content of cobalt and tungsten of the bath decreases (the W/Co ratio and current density being kept constant), because in the dilute bath the current density is nearer to its limiting value at which the maximum percentage of tungsten in the deposit is obtained. The total metal content of cobalt and tungsten, however, has only a minor role in affecting the composition of the deposit. Decrease in the metal content (cobalt and tungsten) of the bath slightly increases the tungsten content of the deposit from the gluconate bath (examples 44 and 45 , table 2), but has no definite trend in the tartrate bath (examples 5 and $6 ; 8$ and $9 ; 13$ and $14 ; 17$ and 18).

Concentration of Ammonium Salts.-As the baths are made alkaline by adding ammonia, which reacts with cobalt salt, some ammonium compounds are present before any further addition is made. Additional large amounts of ammonium salts slightly increases the percentage of tungsten in the deposit. (Table 2: Compare 3 and $4 ; 9$ and 10,16 and 17). Baths made up with ammonium salts of organic acids operate very much like those made with sodium or potassium salts. 
If ammonium compounds are entirely omitted from the plating solution (although the salt of the hydroxy acid is present at a $\mathrm{pH}$ of 8 to 9) the solubility of cobalt and tungsten is reduced and the cathode current efficiencies are so low that the solutions are not suitable for electrodeposition. If the solution contains ammonium salts only, and the hydroxy acids are omitted, the solubilities of cobalt and tungsten are also low, and the cathode current efficiencies are poor. However, as an exception, the ammoniacal ammonium sulfate solution yields fairly good deposits and is nearly practicable.

$\mathrm{pH}$ of the Bath.- No systematic study was made of the effect of the $\mathrm{pH}$ of the solution on the composition of deposit, because at the temperature of operation, loss of ammonia made it impracticable to keep the $\mathrm{pH}$ much above 9 for any length of time. In the presence of an excess of ammonia, at a temperature of $90^{\circ} \mathrm{C}$, the $\mathrm{pH}$ was stable between 8.5 and $9 . \mathrm{A}$ pH lower than 8.0 resulted in increased precipitation of cobalt compounds from the solution on cooling.

Baths Containing Trivalent Cobalt.- Simple compounds containing cobalt in the trivalent state are not stable, but stable complexes containing $\mathrm{Co}^{\mathrm{III}}$ are common, particularly in alkaline solutions. A test was made to determine whether a cobalt solution made up with $\mathrm{Co}^{\mathrm{III}}$ would behave differently from $\mathrm{Co}^{\mathrm{II}}$, and in what state of oxidation the Co would be after a plating solution had been operated for some time. The presence of $\mathrm{Co}^{\text {III }}$ was shown by treating the solution with potassium iodide, acidifying with hydrochloric acid, and then heating in a closed container. This heating was necessary because the cobaltammines do not readily decompose when acidified. The liberated iodine was titrated with thiosulfate. The determination of cobalt in an oxidized ammoniacal solution by this method was quantitative; but this may not have been true in the analysis of the plating solutions, which contained organic constituents.

A cobalt-tungsten plating solution containing $\mathrm{Co}^{\mathrm{III}}$ (made by oxidation of $\mathrm{Co}^{\mathrm{II}}$ with $\mathrm{H}_{2} \mathrm{O}_{2}$ in ammoniacal solution) and Rochelle salt gave deposits very similar in composition and properties to those obtained from the corresponding cobaltous solution. After operation for some time, the cathode efficiencies based on $\mathrm{Co}^{\mathrm{III}}$ rose to 120 percent, which indicates that some of the $\mathrm{Co}^{\mathrm{III}}$ had been reduced. Conversely, operation of the cobaltous alloy plating solution, especially with air agitation, resulted in the formation of a small amount of trivalent cobalt.

A similar comparison was made between cobaltous and cobaltic alloy plating solutions made up from ammoniacal solutions of ammonium sulfate, and containing no organic constituents. There was no difference either in the operation of the plating solutions or in the type of deposit obtained. Therefore it is concluded that the valence of cobalt in the bath is of no practical importance.

Operation and Control of the Plating Process.The cobalt-tungsten plating baths were operated in the manner of any ordinary plating bath. The potential required was about $1 \mathrm{v}$ in a bath where the distance between anode and cathode was about $5 \mathrm{~cm}$. Copper was not very satisfactory for suspending objects in the solution and for use as bus bars, because it corroded in the ammonia vapors and copper compounds dropped into the bath, and contaminated it. Nickel or nickel-plated metal should be used above the bath.

Containers for Plating Solutions.-All of the plating was done in glass vessels. Enamel-lined steel or ceramic tanks also are suitable. Stainless steel tanks may be suitable if the walls are shielded with glass plates. There was some attack of stainless steel immersion heaters, possibly as the result of electrolytic corrosion. Polyethylene can be used to line a tank, but not Saran, which slowly deteriorates in the solution.

Anodes.-Tungsten, cobalt, or a cobalt-tungsten alloy can be used as anodes. Tungsten is the most satisfactory anode, because it corrodes cleanly and smoothly with 100-percent current efficiency. It does not introduce any appreciable amount of insoluble matter into the bath, and the deposits are smooth even though the tungsten anodes are not covered with bags. The area of the tungsten anodes should be not less than about one-third of the cathode area, because otherwise the anodes may become passive. Higher anodic current densities can be used if mildly agitated with air.

When cobalt anodes are used, low anodic current densities should be employed, preferably under $1 \mathrm{amp} / \mathrm{dm}^{2}$, because otherwise the anodes do not corrode well. At higher current densities, a gelatinous pink precipitate forms over the anode and may become detached and suspended in the 
bath. With cobalt anodes under the best conditions, the deposits are not as smooth as with tungsten anodes. Enclosing the cobalt anodes in glass cloth bags yields smoother deposits, but circulation of the solution around the anodes is curtailed, and the bag gradually fills up with a pink precipitate. If cobalt anodes are used, it is more satisfactory to use no anode bags, and to depend on continuous filtration to clarify the bath.

Anodes of a cobalt-tungsten alloy containing 10 to 20 percent of tungsten operate satisfactorily, but anodes of this kind are not commercially available. A bath can be operated with a dual system of tungsten and cobalt anodes, if it is desired to maintain the composition of solution within close limits. For plating the interior of objects, anodes of tungsten or of cobalt-tungsten alloy may be used, but cobalt anodes are not suitable for the above reasons.

If a bath is operated with tungsten anodes, the concentration of tungsten in the solution increases, and eventually it becomes necessary to remove the excess. No convenient chemical method of precipitating tungsten from the alkaline solution was found. In a process occasionally used by us, the bath was electrolyzed with cobalt anodes at a temperature of about $50^{\circ} \mathrm{C}$ (to reduce evaporation and loss of ammonia), at a high-current density, until the excess of tungsten had been replaced by cobalt. On a large scale, the waste cathode deposit thus obtained could subsequently be used as an anode.

Insoluble anodes should not be used in these baths, because the oxidation of the organic constituents at the anode produces deleterious products. After a bath has been operated for some time with insoluble anodes, for example of platinum, the deposits become brighter and more stressed, and pitting, cracking and exfoliation may occur. Filtration through activated charcoal improves the condition of the solution but does not entirely remove the deleterious products.

Control of Ammonia Content.- The most inconvenient feature of these plating solutions is the large loss of water and ammonia at the elevated temperatures employed. These losses were replaced by adding a mixture of ammonium hydroxide and water $(1: 1)$ to keep the solution level constant. No other control of the ammonia content of the solution was required. Bubbling of ammonia gas through the bath was tried but did not prove advantageous. On a large scale it might be practicable to partially enclose the system to reduce the loss of ammonia. In an effort to reduce the loss of water and ammonia, rods and sheets of plastic were floated on the surface, in the manner frequently used for cutting down the spray losses in chromium plating, but this procedure had no effect in reducing the losses from the bath. One method that practically prevented evaporation consisted of floating a layer of melted paraffin, about $1 \mathrm{~cm}$ thick, on the surface. If the objects to be plated were clean, wet, and free from water-break, they could be introduced into the bath through the paraffin layer without any of it adhering sufficiently to prevent plating. On continued operation of the bath, pitting of the deposits began to occur, but this was not necessarily caused by the paraffin. Further consideration of the use of a molten layer over the bath seems warranted.

An effort was made to substitute some less volatile organic amines for ammonia. Four were tried, but the preliminary results were not encouraging. Data on these amines are given in table 5. Only one, hydroxyethylethylenediamine, yielded a high cathode efficiency. The deposits from all the solutions containing amines were inferior, and fell to pieces when the base metal was stripped away. Some amines, for example, guanidine and hydrazine, completely precipitated the cobalt from the alkaline tartrate solution.

Pretreatments for Plating-Methods of Securing Adhesion-Most of the plating was done on steel, although there was no difficulty in plating on copper and brass. Any of the commonly accepted methods of cleaning the metals can be used.

When steel, particularly high-carbon steel, was directly plated in the bath, a high degree of adhesion was not obtained, and it was necessary to study this troublesome problem. The adhesion was measured qualitatively by plating 0.25 $\mathrm{mm}$ or more of the deposit on a steel rod and then attempting to detach the deposit by mechanical means, such as twisting or bending the rod until it broke. The use of etches and strikes alone did not improve the adhesion. A fair degree of adhesion was obtained by first plating the steel with cobalt, and then slightly etching the cobalt anodically with reverse current in the alloy plating bath. The best adhesion was obtained by 
TABLE 5-Deposition of cobalt-tungsten alloys from solutions containing organic amines

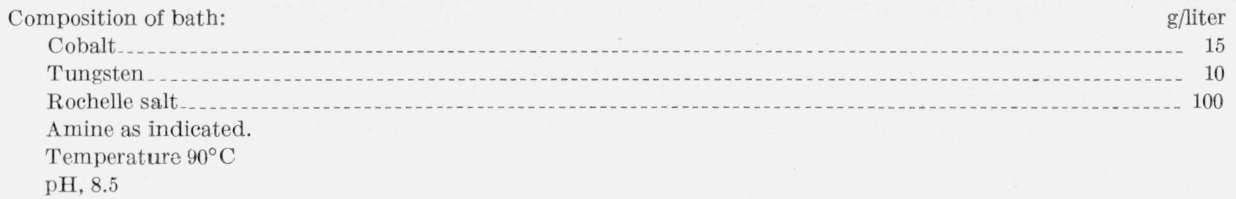

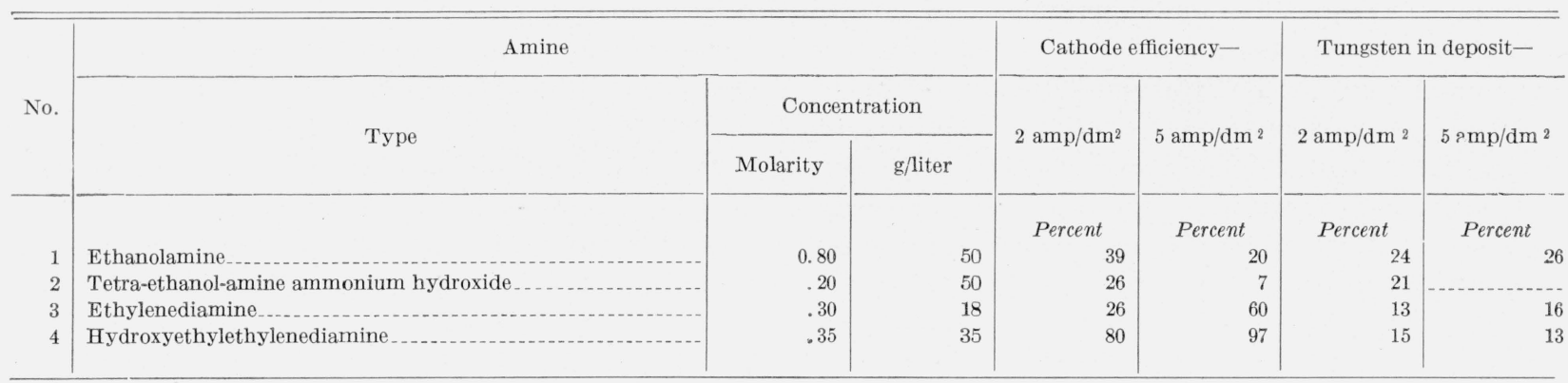

the following process, in which alternating current was used in the final step.

Anodic Etch.-After the steel had been cleaned by any suitable process, it was anodically etched in 70 percent sulfuric acid for 2 minutes at a current density of $25 \mathrm{amp} / \mathrm{dm}^{2}$, and rinsed.

Cobalt Strike.-The steel was plated with cobalt for 3 minutes at a current density of 20 $\mathrm{amp} / \mathrm{dm}^{2}$ in a solution which contained cobalt. $20 \mathrm{~g} /$ liter and $\mathrm{HCl}$ to produce a $\mathrm{pH}$ of 0.5 .

Treatment with alternating current.-After rinsing the object, preferably with 1:1 hydrochloric acid, it was transferred to the plating solution, and alternating current of $0.25 \mathrm{amp} / \mathrm{dm}^{2}$ was passed through the work for 5 to 15 seconds, and then the direct current was immediately turned on.

With this process the adhesion was satisfactory, and a deposit $0.25 \mathrm{~mm}$ thick could not be separated from the base metal by any mechanical means. As alternating current had not previously been utilized for securing adhesion, some further study was made of it, but only the facts pertinent to this alloy system will be mentioned here. The amount of alternating current required for securing good adhesion could be varied over a moderate range, but to some extent it depended on the composition of the bath. Baths low in tungsten but high in cobalt (for example Co $50 \mathrm{~g} /$ liter), required more critical control of the amount of alternating current, for example, smaller amounts of alternating current had to be employed than in dilute bath. If the alternating current was too high, for example $1 \mathrm{amp} / \mathrm{dm}^{2}$ or more, or if the time of treatment was too long, poor adhesion resulted. Within certain limits, higher current densities of alternating current could be used if the time of treatment was correspondingly reduced.

It is important to secure good adhesion of the initial cobalt layer to the steel, otherwise it would be useless to secure a high degree of adhesion of the alloy to the cobalt layer. Good adherence of cobalt to steel (particularly to steel containing $0.5 \%$ or more of carbon), could not be consistently obtained from the standard cobalt plating baths, whether they were made up from chloride or sulfate. No mention of this difficulty is found in the literature. Steps 1 and 2 of the above process provide satisfactory adhesion of cobalt to steel, and both steps are necessary.

Effect of Impurities on the Operation of the Bath.The alloy plating solution is not very sensitive to the metallic impurities that might become introduced in a plating room. The effects of impurities were determined by adding small amounts of them to the solution containing: cobalt, 25 $\mathrm{g} /$ liter; tungsten, $25 \mathrm{~g}$ /liter; and Rochelle salt, 400 $\mathrm{g} /$ liter. The addition of copper, $0.2 \mathrm{~g} /$ liter resulted in the production of a bright deposit, but larger amounts yielded a nodular or spongy, dark deposit. Zinc had little effect on the deposit when added in quantities up to $10 \mathrm{~g} /$ liter, and tin likewise had no deleterious effect on the deposit, but caused a precipitate to form in the bath when its concentration became as high as $25 \mathrm{~g} /$ liter. Spectrochemical examination of the deposits obtained from the solutions contaminated with zinc and tin showed the presence of moderate amounts of 
these metals, which, however, may have been present as basic inclusions. Lead caused uneven plating if present in concentrations higher than $0.2 \mathrm{~g} /$ /iter; and if present to the extent of $5 \mathrm{~g}$ /liter, lead plated out of the solution more readily than the alloy. Addition of $0.2 \mathrm{~g}$ /liter of cadmium caused a lowering of the cathode efficiency, and in larger concentrations it produced spongy deposits similar to those obtained with copper. Iron did not affect the deposit when present to the extent of $5 \mathrm{~g}$ /liter, but caused a gradual precipitation of iron compounds from the solution. Chromic acid had no appreciable effect when added in small quantities, but when present to the extent of $5 \mathrm{~g}$ /liter, plating ceased. However, after the hot solution had stood for several hours, the chromic acid was reduced and the bath operated satisfactorily once more. Small quantities of sodium cyanide (1 g/liter) had no effect, but $5 \mathrm{~g}$ /liter produced a precipitate.

Plating with Alternating Current Superimposed on Direct Current.- Some deposits were plated using both direct current and 60-cycle alternating current in different ratios. The resultant current was pulsating direct current except when a high proportion of alternating current was used, in which case there was a momentary reversal of current at the cathode. The deposits produced with the mixed alternating and direct currents had about the same composition as those obtained with direct current alone and were similar in appearance. No obvious advantage was found from superimposing the alternating current.

Stress in Deposits During Deposition.-Attempts were made to produce thick separable deposits on a surface upon which the alloy would not be strongly adherent, for example on lead, to determine the feasibility of using the alloy for electroforming. When the alloy became more than 0.5 $\mathrm{mm}$ thick, it tended to crack spontaneously, although this did not occur when the alloy was plated adherently on steel. The stress developed during plating was qualitatively measured with a contractometer and was found to be slightly less than that occurring in an ordinary acid-cobalt bath, but slightly greater than that occurring in a Watts nickel bath. These few measurements did not throw light on the cause of the cracking.

Stability of Plating Solutions.-The alloy plating solutions used in the investigation were chiefly the
Rochelle salt baths, which were fairly stable. A bath of a few liters was operated for a period long enough to deposit an amount of cobalt equal to that initially present, without showing signs of deterioration. When these solutions are allowed to stand uncovered, they gradually lose ammonia, and a pink solid precipitates, and redissolves in the bath only slowly with the addition of ammonia and the application of heat. Therefore the baths should be kept covered when not in use.

\section{Electrodeposition of Nickel-Tungsten Alloys}

Literature.-As more work has been reported on the nickel-tungsten alloys than on the other tungsten alloys, a more detailed discussion is desirable. Fink and Jones [13] used a carbonate solution for the electrodeposition of a nickeltungsten alloy, and obtained deposits that were only a few microns thick. Our experience with the plating bath of Holt and Nielson [17], which consisted of a solution of nickel sulfate and sodium tungstate at a low $\mathrm{pH}$, was that the deposits were low in tungsten, usually not over 7 percent, and that deposits over $0.025 \mathrm{~mm}$ thick were rough. The numerous patents of Armstrong and Menefee [1 to 8] make broad claims for other metals and operating conditions, but limit their examples to the codeposition of nickel-tungsten alloys from baths with a $\mathrm{pH}$ below 7 , which contain, in addition to the alloying metals, fluorides, phosphates, borates, citrates, and ammonium salts. The deposits that were obtained by their process were not any sounder than those plated from the simpler solution of Holt and Nielson; but higher tungsten contents could be obtained. Although the importance of fluorides in these baths is emphasized, neither fluorides, borates, or phosphates appear to be of any value. The deposits from the ammoniacal solution recommended by Goltz and Kharlamov [14] contained 20 percent of tungsten, and were hard, but because of the excessively high current density used (20 to 40 $\left.\operatorname{amp} / \mathrm{dm}^{2}\right)$, the deposits were porous and cracked. If their solution is electrolyzed at a current density of $2 \mathrm{amp} / \mathrm{dm}^{2}$, a deposit is obtained that is lower in tungsten but much sounder. As the recently published paper of Vaaler and Holt [25] described plating conditions similar to those that are reported here, its discussion will be presented later in this paper.

Less emphasis has been put on the nickel- 
tungsten than on the cobalt-tungsten system, because the cobalt alloys show a wider range of properties, can be obtained with higher percentages of tungsten, and exhibit precipitationhardening to a greater extent than the nickel alloys.

Solubility Relations.-Plating solutions containing hydroxy-acids and ammonium salts, similar to those used for the cobalt alloys, were used for depositing the nickel alloys. The tartrate and citrate solutions were the most satisfactory. Solubility experiments showed less constancy of the solubility product of nickel and tungsten than of the cobalt and tungsten, but this relation serves as a convenient indicator of the solubility relations in a variety of solutions, as shown in table 6 .

TABLE 6.-Solubility relations of nickel and tungsten in ammonical solutions at $\mathrm{pH} 8.5$

[The citrate and tartrate solutions contained $50 \mathrm{~g} /$ liter of ammonium chloride]

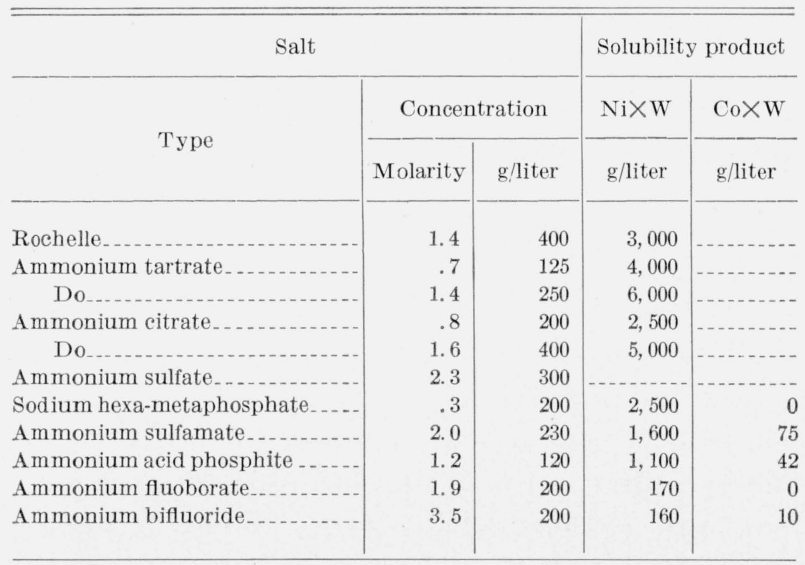

In general, the mutual solubilities of nickel and tungsten in the electrolyte were greater than the mutual solubilities of cobalt and tungsten. For example, in an ammonium tartrate solution containing tungstate, the concentration of nickel may be as high as $100 \mathrm{~g} /$ liter, whereas that of cobalt cannot be much above $50 \mathrm{~g} /$ liter without eventually precipitating. The solubility products of nickel and tungsten in the solutions containing only inorganic salts are much higher than for cobalt and tungsten, and indicate a greater possibility of preparing an inorganic bath for the nickel than for the cobalt alloy. Some data for the latter are given in table 6 for comparative purposes. The large solubility product of nickel and tungsten in the hexametaphosphate solution is noteworthy.
D. Factors Affecting the Composition of the Deposit.-Nickel alloys could not be obtained with as high a content of tungsten as the cobalt alloys. The limit of the tungsten content in the nickel alloys was about 35 percent, as compared with about 50 percent for the cobalt-tungsten alloys. The effects of the variables of bath composition and operating conditions were similar to those observed with the cobalt system, and hence the discussion of this subject can be abridged except where the two systems differ. The relations of the composition of the plating solutions and of the deposits are illustrated in table 7 ; and the effects of current density in table 8. Most of the data were obtained with solutions of citrates and tartrates, the latter solution producing the soundest deposits.

The main conclusions are as follows:

1. The tungsten-nickel ratio of the bath (fig. 2 and fig. 3) has the most important effect on the

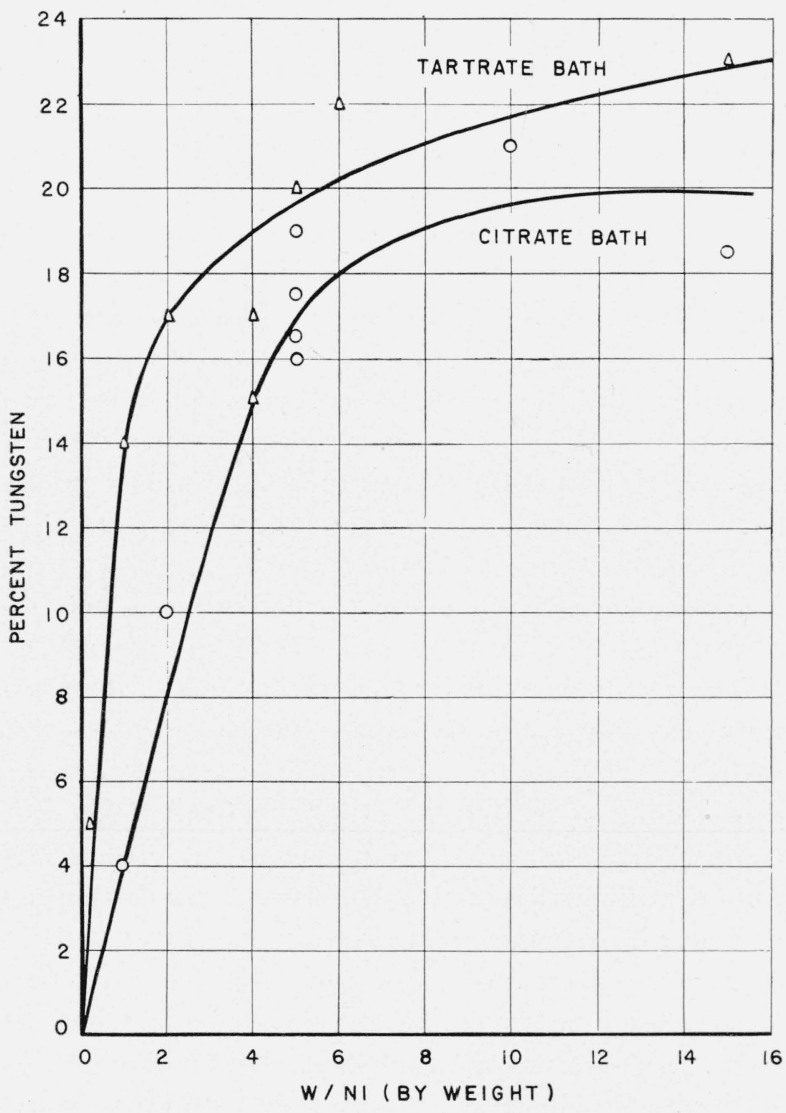

FIGURE 2.-Effect of tungsten-nickel ratio on the percentage of tungsten in the deposit from ammonium tartrate and sodium citrate alloy baths of various compositions at a current density of $2 \mathrm{amp} / \mathrm{dm}^{2}$. 
TABLE 7.-Composition of nickel-tungsten alloys deposited from ammoniacal solutions of organic salts

[Each solution contained $50 \mathrm{~g} /$ liter of ammonium chloride; temperature $90^{\circ} \mathrm{C} ; \mathrm{pH} 8.5$ ]

\begin{tabular}{|c|c|c|c|c|c|c|c|c|c|c|c|c|}
\hline \multirow{4}{*}{ No. } & \multicolumn{8}{|c|}{ Bath composition } & \multicolumn{2}{|c|}{ Cathode efficiency- } & \multicolumn{2}{|c|}{ Tungsten in deposit- } \\
\hline & \multirow{3}{*}{$\begin{array}{c}\mathrm{W} / \mathrm{Ni} \\
\text { (weight) }\end{array}$} & \multicolumn{2}{|c|}{$\mathrm{Ni}$} & \multicolumn{2}{|c|}{ W } & \multicolumn{3}{|c|}{ Organic salt } & \multirow{3}{*}{$2 \mathrm{amp} / \mathrm{dm}^{2}$} & \multirow{3}{*}{$5 \mathrm{amp} / \mathrm{dm}^{2}$} & \multirow{3}{*}{$2 \mathrm{amp} / \mathrm{dm}^{2}$} & \multirow{3}{*}{$5 \mathrm{amp} / \mathrm{dm}^{2}$} \\
\hline & & \multirow{2}{*}{$\underset{\text { larity }}{\text { Mo- }}$} & \multirow{2}{*}{$\mathrm{g} /$ liter } & \multirow{2}{*}{$\begin{array}{l}\text { Mo- } \\
\text { larity }\end{array}$} & \multirow{2}{*}{$\mathrm{g} /$ liter } & \multirow{2}{*}{ Type } & \multicolumn{2}{|c|}{ Concentration } & & & & \\
\hline & & & & & & & $\underset{\text { larity }}{\text { Mo- }}$ & g/liter & & & & \\
\hline
\end{tabular}

CITRATE

\begin{tabular}{|c|c|c|c|c|c|c|c|c|c|c|c|c|}
\hline $1 \ldots \ldots$ & 1 & 0.68 & 40 & 0.20 & 35 & $\mathrm{Na}$ & 0.60 & 200 & $\begin{array}{r}\text { Percent } \\
81\end{array}$ & $\begin{array}{l}\text { Percent } \\
81\end{array}$ & ${ }_{4}^{\text {Percent }}$ & $\begin{array}{l}\text { Percent } \\
9\end{array}$ \\
\hline 2 - 2 & 2 & .34 & 19 & .20 & 35 & $\mathrm{Na}$ & .30 & 100 & 95 & 77 & 10 & 15 \\
\hline 3 - 3 & 3 & .11 & 7 & .19 & 17 & $\mathrm{Na}$ & .30 & 100 & $\ldots$ & 80 & $\ldots$... & 25 \\
\hline 4 & 4 & .42 & 25 & .54 & 100 & $\mathrm{NH}_{4}$ & 1. 60 & 400 & 61 & 64 & 12 & 12 \\
\hline $5 \quad 5 \ldots$ & 5 & .11 & 7 & .20 & 35 & $\mathrm{Na}$ & 0.30 & 100 & 88 & 63 & 16 & 26 \\
\hline $6 \ldots \ldots$ & 5 & .11 & 7 & .20 & 35 & $\mathrm{Na}$ & .65 & 230 & 47 & 63 & 17 & 26 \\
\hline $7 \mathrm{a} \ldots \ldots \ldots$ & 5 & .21 & 13 & .37 & 68 & $\mathrm{Na}$ & .60 & 200 & 88 & 86 & 16 & 31 \\
\hline $8^{b}+\ldots$ & 5 & .11 & 7 & .20 & 35 & $\mathrm{Na}$ & .30 & 100 & 75 & 53 & 19 & 25 \\
\hline 9 & 10 & .11 & 7 & .37 & 68 & $\mathrm{Na}$ & .30 & 100 & 81 & 81 & 21 & 29 \\
\hline $10 \ldots$ & 15 & .11 & 7 & .52 & 95 & $\mathrm{Na}$ & .30 & 100 & 97 & 96 & 18 & 26 \\
\hline
\end{tabular}

TARTRATE

\begin{tabular}{|c|c|c|c|c|c|c|c|c|c|c|c|c|}
\hline $11 \ldots$ & 0.2 & 0.42 & 25 & 0.03 & 5 & $\mathrm{NH}_{4}$ & 1. 30 & 245 & 95 & 96 & 5 & 5 \\
\hline 12 & 1 & .42 & 25 & .13 & 25 & $\mathrm{NH}_{4}$ & 1. 30 & 245 & 94 & & 14 & - \\
\hline 13 & 1 & .68 & 40 & .20 & 35 & $\mathrm{Na}, \mathrm{K}$ & 0.70 & 200 & $\ldots$ & 95 & c 7 & 5 \\
\hline 14 & 2 & .42 & 25 & .27 & 50 & $\mathrm{NH}_{4}$ & 1.30 & 245 & 89 & & 17 & -.. \\
\hline 15 & 4 & .42 & 25 & .54 & 100 & $\mathrm{Na}, \mathrm{K}$ & 1.40 & 400 & 90 & 92 & 9 & 13 \\
\hline 16 & 4 & .42 & 25 & .54 & 100 & $\mathrm{NH}_{4}$ & 0.65 & 120 & 60 & 84 & 15 & 20 \\
\hline 17 & 4 & .42 & 25 & .54 & 100 & $\mathrm{NH}_{4}$ & 1. 30 & 245 & 80 & 77 & 17 & 21 \\
\hline 18 & 5 & .08 & 5 & .13 & 25 & $\mathrm{NH}_{4}$ & 1.30 & 245 & 55 & 52 & 21 & 26 \\
\hline 19 & 6 & .34 & 20 & .63 & 115 & $\mathrm{NH}_{4}$ & 1.30 & 245 & 75 & & 22 & -.. \\
\hline
\end{tabular}

HYDROXYACETATE

\begin{tabular}{|c|c|c|c|c|c|c|c|c|c|c|c|c|}
\hline $20 \ldots \ldots \ldots$ & 0.3 & 1. 70 & 100 & 0.16 & 30 & K & 2.5 & 300 & & & 4 & 5 \\
\hline $21^{\mathrm{a}}-\ldots+\ldots-1, \ldots$ & .3 & 1. 70 & 100 & .16 & 30 & $\mathrm{~K}$ & 5. 0 & 600 & & & 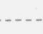 & 1 \\
\hline 22 & .3 & 0.85 & 50 & .08 & 15 & $\mathrm{NH}_{4}$ & 2.5 & 250 & & 100 & 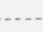 & 2 \\
\hline $23 \ldots$ & .6 & .85 & 50 & .16 & 30 & $\mathrm{NH}_{4}$ & 5.0 & 500 & & & & 13 \\
\hline 24 & 4 & .42 & 25 & .54 & 100 & $\mathrm{NH}_{4}$ & 5. 0 & 500 & 98 & 76 & 17 & 21 \\
\hline
\end{tabular}

SACCHARATE

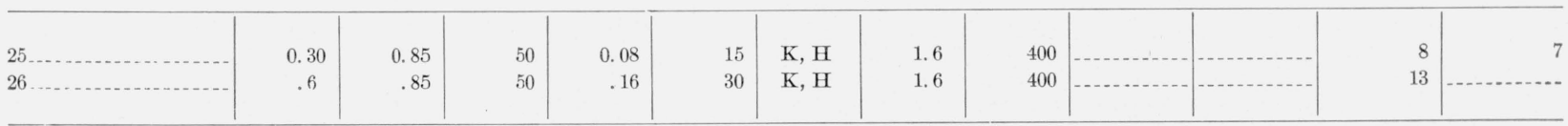

GLYCINATE

\begin{tabular}{|c|c|c|c|c|c|c|c|c|c|c|c|}
\hline $27 \ldots$ & 0.3 & 1. 7 & 100 & 0.16 & 30 & $\mathrm{~K}$ & 2.7 & 300 & 90 & 5 & 11 \\
\hline \multicolumn{12}{|c|}{ INORGANIC } \\
\hline $28 \mathrm{~d}$ & 0.4 & 0.3 & 18 & 0.04 & 8 & & & & & 10 & 14 \\
\hline
\end{tabular}

s Bath contained $\mathrm{NH}_{4} \mathrm{Cl}, 100$ g/liter.

b Bath contained $\mathrm{NH}_{4} \mathrm{Cl}, 200 \mathrm{~g} /$ liter.

c $3 \mathrm{amp} / \mathrm{dm}^{2}$.

d Bath contained $\left(\mathrm{NH}_{4}\right)_{2} \mathrm{SO}_{4}, 400$ g/liter. 


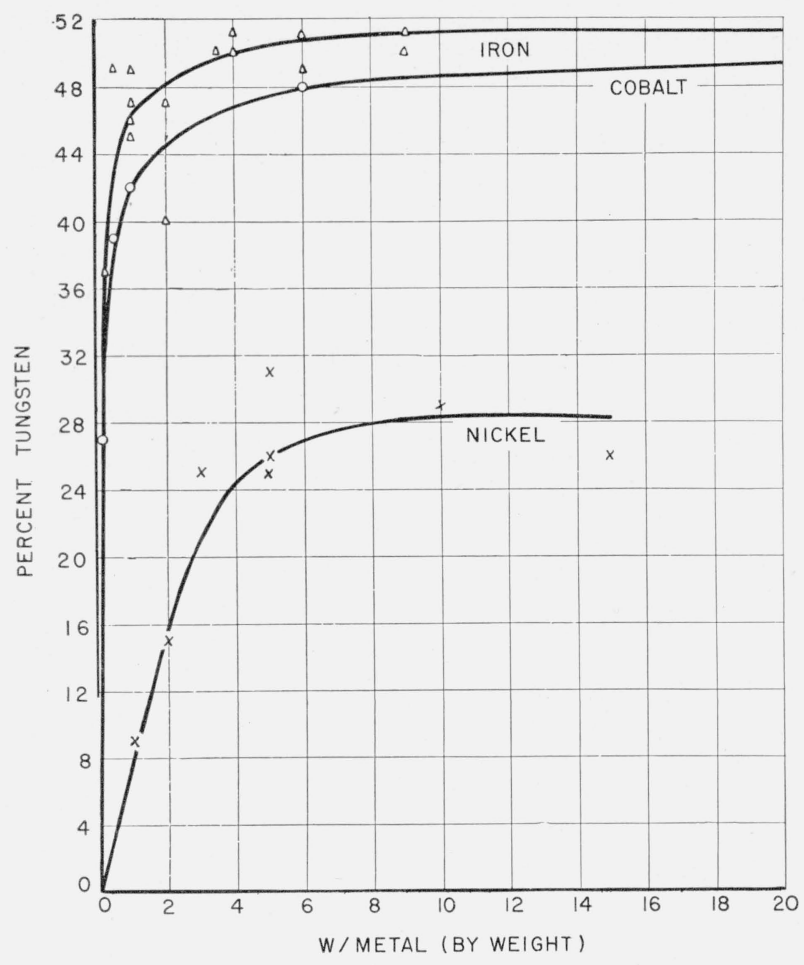

Figure 3.-Comparison of effect of tungsten-metal ratio on the percentage of tungsten in the deposit plated from nickel, cobalt, and iron-tungsten alloy citrate baths of various compositions at a current density of $5 \mathrm{amp} / \mathrm{dm}^{2}$. composition of the deposits. When this ratio exceeds 4 , the increase of tungsten in the deposit is slight. In no instance was a deposit obtained, (as was the case for the cobalt alloy) in which the ratio of tungsten to nickel was higher in the deposit than in the bath.

2. The content of tungsten in the deposit increases with current density (table 8 ). It will be recalled that in the citrate cobalt-alloy solution, the composition of the deposit was almost unaffected by variations of current density. This behavior is not shown by the citrate nickel-alloy plating solution. The deposits obtained from tartrate and other solutions at a current density of $5 \mathrm{amp} / \mathrm{dm}^{2}$ were not as sound as those obtained at a current density of $2 \mathrm{amp} / \mathrm{dm}^{2}$, and usually developed cracks when the copper supporting tube was stripped away. It has not been determined whether this cracking is related to the composition of the deposit or to the precipitation of inclusions at the higher current density.

3. The type of organic acid employed (if any) has very little effect on the composition of the deposit, in contrast to the cobalt alloy systems in which considerably more tungsten is codeposited from a citrate solution than from any other.

TABLE 8. Effect of current density on the composition of nickel-tungsten alloys

[Each solution contained ammonium chloride, $50 \mathrm{~g} /$ liter. Temperature $\left.90^{\circ} \mathrm{C} ; \mathrm{pH} 8.5.\right]$

\begin{tabular}{|c|c|c|c|c|c|c|c|c|c|c|}
\hline \multirow{3}{*}{$\begin{array}{c}\text { No. } \\
\text {. }\end{array}$} & \multicolumn{7}{|c|}{ Bath composition } & \multirow{3}{*}{$\begin{array}{l}\text { Current } \\
\text { density }\end{array}$} & \multirow{3}{*}{$\begin{array}{l}\text { Cathode } \\
\text { efficiency }\end{array}$} & \multirow{3}{*}{$\begin{array}{l}\text { Tungsten } \\
\text { in deposit }\end{array}$} \\
\hline & \multirow{2}{*}{$\underset{\text { (weight) }}{\mathrm{W} / \mathrm{Ni}}$} & \multicolumn{2}{|c|}{$\mathrm{Ni}$} & \multicolumn{2}{|c|}{ W } & \multicolumn{2}{|c|}{$\begin{array}{l}\text { Sodium citrate con- } \\
\text { centration }\end{array}$} & & & \\
\hline & & Molarity & $\mathrm{g} /$ liter & Molarity & $\mathrm{g} /$ liter & Molarity & $\mathrm{g} /$ liter & & & \\
\hline $1 \ldots$ & 1 & 0.68 & 40 & 0.20 & 35 & 0.6 & 200 & $a m p / d m^{2}$ & $\begin{array}{r}\text { Percent } \\
81\end{array}$ & Percent \\
\hline 2 & 1 & .68 & 40 & .20 & 35 & .6 & 200 & 5 & 81 & $\begin{array}{l}4 \\
9\end{array}$ \\
\hline 3 & 1 & .68 & 40 & .20 & 35 & .6 & 200 & 10 & $\ldots$ & 13 \\
\hline 4 & 2 & .34 & 19 & .20 & 35 & .3 & 100 & 2 & 95 & 10 \\
\hline 5 & 2 & .34 & 19 & .20 & 35 & .3 & 100 & 5 & 77 & 15 \\
\hline $6 \ldots \ldots$ & 2 & .34 & 19 & .20 & 35 & .3 & 100 & 10 & 88 & 16 \\
\hline 7 & 2 & .34 & 19 & .20 & 35 & .3 & 100 & 20 & 82 & 26 \\
\hline 8 & 2 & .34 & 19 & .20 & 35 & .3 & 100 & 30 & 93 & 25 \\
\hline 9 & 5 & .22 & 13 & .37 & 68 & .6 & 200 & 2 & 88 & 16 \\
\hline $10 \ldots$ & 5 & .22 & 13 & .37 & 68 & .6 & 200 & 5 & 86 & 31 \\
\hline $11 \ldots$ & 5 & .22 & 13 & .37 & 68 & .6 & 200 & 10 & 79 & 26 \\
\hline 12 & 5 & .22 & 13 & .37 & 68 & .6 & 200 & 20 & 82 & 33 \\
\hline 13 & 5 & .22 & 13 & .37 & 68 & .6 & 200 & 30 & 51 & 33 \\
\hline 14 & 15 & .11 & 7 & .52 & 95 & .3 & 100 & 2 & 97 & 18 \\
\hline 15 & 15 & .11 & 7 & .52 & 95 & .3 & 100 & 5 & 96 & 26 \\
\hline 16 & 15 & .11 & 7 & .52 & 95 & .3 & 100 & 10 & 94 & 37 \\
\hline 17 & 15 & .11 & 7 & .52 & 95 & .3 & 100 & 20 & 62 & 38 \\
\hline
\end{tabular}


Summary from Table \%.-Effect of type of plating solution on the composition of nickel-tungsten alloys.

Ni, 25 g/liter; W, 100 g/liter

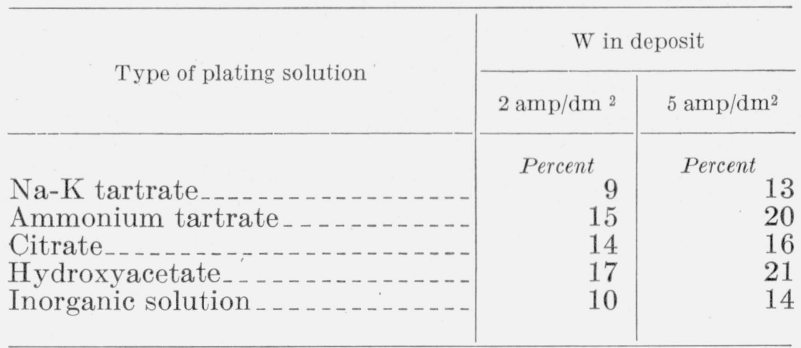

4. From data available, it does not appear that variations in the concentration of the salts of organic acids or in the total concentration of nickel and tungsten have any important effect on the composition of the deposit.

5. As with the cobalt system, the addition of ammonium salts up to several hundred grams per liter to the baths, which already contain ammonium compounds as made up, has little effect on the deposits except to darken the color. Alkaline plating solutions prepared from salts of the hydroxy acids, with no ammonium compounds present, operate very poorly. The mutual solubility of nickel and tungsten is much reduced, and the cathode efficiency is only a few percent. Addition of a small amount of ammonium compounds raises the efficiency to 90 percent. However, an ammonia-free citrate plating solution, which initially had a very low cathode current efficiency, improved considerably in this respect after being used for several hours.

Solutions containing inorganic ammonium salts and no salts of hydroxy acids do not operate as well as the preferred type of bath, because of the lower solubility of the metals and the lower cathode efficiency. These solutions are, however, much more satisfactory than those containing hydroxy acids but no ammonium salts. As compared with the preferred type of bath, they have the advantage that an insoluble anode can be used in them.

In the tartrate bath a difference was noted in the composition of the deposits $(12,13,15$, and 17 in table 7) according to whether the solution was made up with Rochelle salt or with ammonium tartrate. From the latter solution the deposits contained significantly more tungsten. This effect is not caused by the presence of a larger quantity of ammonium salts, as adding large quantities of ammonium salts to the Rochelle salt solution did not effect the composition of the deposits. It may be caused by the presence of the sodium or potassium salts, though it is rather unusual for inert ions such as these to influence the composition of an alloy deposit.

Comparison with Work of Vaaler and Holt.-It is of interest to compare the above observations with those of Vaaler and Holt [25], who worked mainly with citrate solutions. Their range of compositions of baths and alloys and their operating conditions are similar to those reported here. The main difference is that they used temperatures only up to $70^{\circ} \mathrm{C}$, whereas the best quality of deposit was obtained in the present work at higher temperatures. Occasionally they used insoluble anodes, which form deleterious products in the bath and produce bright, strained, and pitted deposits. Current densities of 7 to $15 \mathrm{amp} / \mathrm{dm}^{2}$, such as they used, are too high for the production of deposits sound enough for commercial use.

Operation of Plating Solutions.-Much of what has been said in regard to the control of the temperature, $\mathrm{pH}$, ammonia content, anodes, and adhesion in cobalt-tungsten alloy solutions applies to the nickel-tungsten alloy solutions. The anode corrosion of nickel in these baths is poorer than that of cobalt, and the anode current density can not exceed $0.3 \mathrm{amp} / \mathrm{dm}^{2}$, without forming a precipitate on the anode. The effects of many impurities in the solution have not been studied, but small amounts of copper produce a bright deposit and larger quantities, a rough, dark deposit. The nickel-alloy solutions have less tendency than the cobalt-tungsten solutions to precipitate on long standing.

\section{Electrodeposition of Iron-Tungsten Alloys}

General.-Our knowledge concerning the irontungsten plating solutions is less complete than that for the other two alloys, because the former are more difficult to investigate. The iron-tungsten alloy systems exhibit considerable differences from those of cobalt and nickel alloys. In some respects, this is the most interesting of the three systems studied, because the tungsten contents of the deposits are higher, and because some of the deposits are harder even than chromium.

One of the main difficulties involved in the plating solutions for the iron-tungsten system is 
that the iron can exist in two states of oxidation. Plating is more readily carried out in the solutions of Fe II than of Fe III, but the alkaline solutions of ferrous compounds oxidize rapidly in the air. Hence, it is not practicable to know exactly the composition of a bath that has been in operation for some time. Because the solubilities of the ironorganic complexes are not as high as those of cobalt and nickel, a wide range of concentrations is not feasible. The cathode efficiencies are lower, for example, about 50 percent. This situation increased the difficulty of plating thick deposits for physical examination.

Solubility Relations of the Iron-Tungsten Plating Solutions.-No quantitative solubility studies were made on the iron-tungsten plating solutions, as was done for the nickel and cobalt solutions. Ferric compounds had a higher solubility than ferrous compounds. In the citrate bath maximum concentrations of about $25 \mathrm{~g}$ each of iron and tungsten could be obtained but the solutions were not as stable as the corresponding nickel and cobalt solutions, and iron tungstates gradually precipitated on operation. The tartrate solutions were not satisfactory because of the low solubility of terrous compounds in them.

In making up the alloy plating solution, precipitation was likely to occur if the salts were not dissolved in the right order. The citrate, iron sulfate, and the ammonium salts were dissolved successively, and the solution was made ammoniacal. The tungstate was dissolved separately and was made ammoniacal before adding it to the iron solution.

Factors Affecting Composition of Deposit.-The outstanding characteristic of the deposition of iron-tungsten alloys is that, despite large changes in the composition of the plating solution and the conditions of operation, the deposit maintains a fairly constant composition, with about 50 percent of tungsten. This behavior is illustrated in tables 9 and 10 and figure 3 in which all of the deposits contain between 30 and 60 percent of tungsten, and most of them between 40 and 55 percent. It has not proved expedient to produce low-tungsten alloys because of the difficulty in controlling the small concentration of tungsten that is required in the plating solution.

As the composition of the deposit does not vary greatly with a change of variables, no detailed analysis of these effects is included, particularly because the reproducibility of the composition of the deposits was not very high. The range of variations is shown in tables 9 and 10 . The only condition that made a decided change in the composition of the deposit was the use of a malate solution (table 9) that yielded deposits containing about 30 percent of tungsten, as compared with 45 or 50 percent for the citrate solutions. The gluconate and tartrate solutions yielded deposits with about the same composition as did the citrate. The tartrate solution is not satisfactory because iron tartrates gradually precipitate from it on heating.

In the iron-tungsten system, the tungsten usually behaves as the less noble metal, that is, the metal ratio, W/Fe, of the deposit was usually smaller than that of the solution. As with the cobalt-tungsten alloys, however, certain of the plating solutions yielded deposits that had a larger ratio than the solution, thus indicating a reversal of the relative potentials of the codeposited metals. This is illustrated by No. 1, table 9 where the metal ratio of the deposit is 1 and that of the solution is 0.5 , and by No. 17 , table 9, where the metal ratio of the deposit is 0.5 , while that of the solution is 0.2 . This apparent shifting of the deposition characteristic of tungsten is shown with both cobalt and iron only in solutions with a low concentration of tungsten. If more tungsten is added to a solution, the tungsten content of the deposit approaches a limit, while the metal ratio of the solution increases and soon exceeds the maximum that the deposit is capable of attaining.

The main effect of the composition and operating conditions of the solution is upon the cathode current efficiency. Ferrous solutions [15 to 22] have cathode efficiencies of 65 to 85 percent, and ferric solutions [1 to 14] of 30 to 50 percent. Increasing the citrate content materially lowers the cathode efficiency [compare 3 and 4; 7 and $8 ; 11$ and $13 ; 20$ and 21]. The cathode efficiency (table 10 ) at $50^{\circ} \mathrm{C}$ is considerably lower than at $70^{\circ}$ and $90^{\circ} \mathrm{C}$.

Operation of Plating Solutions.-The operation of the ferrous solutions was not satisfactory because they tend to oxidize readily. By using a deep vessel and passing a slow stream of carbon dioxide over the solution, oxidation could be retarded. In solutions operated in the air, 50 percent or more of the iron became ferric. On standing, the solu- 
TABLE 9.-Composition of iron-tungsten alloys deposited from ammoniacal solutions

[Each solution conta ined additional ammonium salts, 50-100 g/liter, unless otherwise indicated. Baths were operated at a pH of 8.5 to 9 , and above $\left.90^{\circ} . \mathrm{C}\right]^{\text {] }}$

\begin{tabular}{|c|c|c|c|c|c|c|c|c|c|c|c|c|c|c|}
\hline \multirow{4}{*}{ No. } & \multicolumn{8}{|c|}{ Bath composition } & \multirow{2}{*}{\multicolumn{3}{|c|}{ Cathode efficiency }} & \multirow{2}{*}{\multicolumn{3}{|c|}{ Tungsten in deposit }} \\
\hline & \multirow{3}{*}{$\begin{array}{c}\mathrm{W} / \mathrm{Fe} \\
\text { (weight) }\end{array}$} & \multicolumn{2}{|c|}{$\mathrm{Fe}$} & \multicolumn{2}{|c|}{ W } & \multicolumn{3}{|c|}{ Organic salt } & & & & & & \\
\hline & & \multirow{2}{*}{ Molarity } & \multirow{2}{*}{$\mathrm{g} /$ liter } & \multirow{2}{*}{ Molarity } & \multirow{2}{*}{ g/liter } & \multirow{2}{*}{ Type } & \multicolumn{2}{|c|}{ Concentration } & \multirow{2}{*}{$\begin{array}{c}2 \\
\mathrm{amp} / \mathrm{dm}^{2}\end{array}$} & \multirow{2}{*}{$\stackrel{5}{\mathrm{amp} / \mathrm{dm}^{2}}$} & \multirow{2}{*}{$\begin{array}{c}10 \\
\mathrm{amp} / \mathrm{dm}^{2}\end{array}$} & \multirow{2}{*}{$\underset{\mathrm{amp} / \mathrm{dm}^{2}}{2}$} & \multirow{2}{*}{$\begin{array}{c}5 \\
\mathrm{amp} / \mathrm{dm}^{2}\end{array}$} & \multirow{2}{*}{$\begin{array}{c}10 \\
\operatorname{amp} / \mathrm{dm}^{2}\end{array}$} \\
\hline & & & & & & & Molarity & $\mathrm{g} /$ liter & & & & & & \\
\hline
\end{tabular}

\section{FERRIC CITRATE BATH}

\begin{tabular}{|c|c|c|c|c|c|c|c|c|c|c|c|c|c|c|}
\hline $1 \ldots$ & 0.5 & 0.14 & 8 & 0.02 & 4 & $\mathrm{Na}$ & 0.30 & 100 & $\begin{array}{r}\text { Percent } \\
47\end{array}$ & $\begin{array}{r}\text { Percent } \\
29\end{array}$ & Percent & Percent & $\begin{array}{r}\text { Percent } \\
49\end{array}$ & $\begin{array}{r}\text { Percent } \\
\\
55\end{array}$ \\
\hline $2 \ldots \ldots$ & 1.0 & .14 & 8 & .04 & 8 & $\mathrm{Na}$ & .30 & 100 & 53 & 40 & & 53 & & \\
\hline $3 \ldots$ & 2. 0 & .27 & 16 & .20 & 35 & $\mathrm{Na}$ & .30 & 100 & & 43 & & 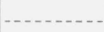 & 47 & 48 \\
\hline $5 \ldots \ldots$ & 3.0 & .21 & 12 & .20 & 35 & $\mathrm{Na}$ & .30 & 100 & 46 & 38 & & 51 & 46 & \\
\hline $6 \ldots \ldots$ & 3.5 & .14 & 8 & .15 & 28 & $\mathrm{Na}$ & .30 & 100 & & 47 & & & 50 & \\
\hline $7 \ldots \ldots \ldots$ & 4. 0 & .14 & 8 & .20 & 35 & $\mathrm{Na}$ & .30 & 100 & & 58 & 21 & & 50 & 52 \\
\hline $10 \ldots$ & 6.0 & .10 & 6 & .20 & 35 & $\mathrm{Na}$ & .30 & 100 & & 40 & & & 51 & \\
\hline $11 \ldots$ & 9.0 & .14 & 8 & .40 & 72 & $\mathrm{Na}$ & .30 & 100 & & 42 & & & 51 & \\
\hline 12 & 9.0 & .07 & 4 & .20 & 35 & $\mathrm{Na}$ & .30 & 100 & 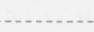 & 29 & 20 & & 50 & \\
\hline $13 \ldots$ & 9.0 & .14 & 8 & .40 & 70 & $\mathrm{Na}$ & .60 & 200 & & 23 & & & 50 & \\
\hline $14 \ldots$ & 175 & .003 & 0.2 & .20 & 35 & $\mathrm{Na}$ & .30 & 100 & & 12 & & & 63 & \\
\hline
\end{tabular}

FERROUS CITRATE BATH

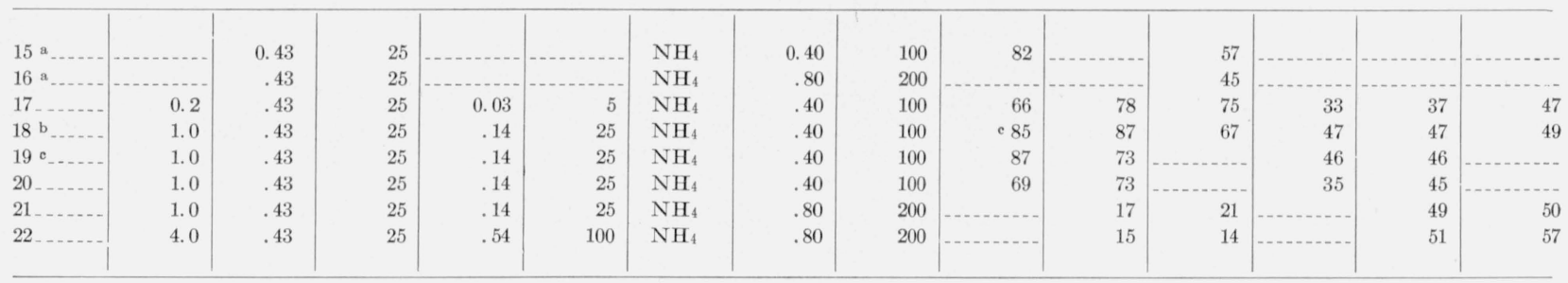

\section{FERRIC GLUCONATE BATH}

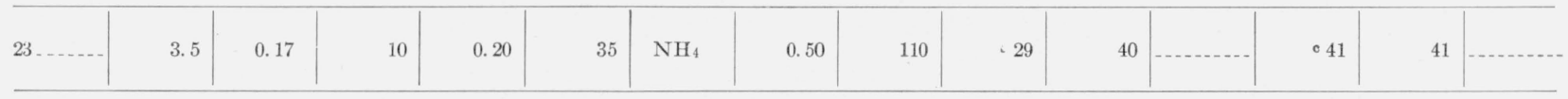

FERRIC MALATE BATH

\begin{tabular}{l|l|l|l|r|r|r|r|r|r|r|r}
\hline $24 \ldots \ldots$ & 1 & 0.43 & 25 & 0.14 & 25 & $\mathrm{NH}_{4}$ & 1.5 & 250 & $\ldots$ & 21 & 52 \\
\hline
\end{tabular}

\section{FERROUS MALATE BATH}

\begin{tabular}{|c|c|c|c|c|c|c|c|c|c|c|c|c|c|c|}
\hline \multicolumn{15}{|c|}{ FERRIC TARTRATE BATH } \\
\hline $26 \ldots \ldots$ & 4 & 0.14 & 8 & 0.20 & 35 & $\mathrm{NH}_{4}$ & 0.5 & 100 & & 44 & & & 35 & \\
\hline
\end{tabular}

\section{FERROUS TARTRATE BATH}

\begin{tabular}{l|l|l|l|l|l|l|l|l|r|r|r}
\hline $27 \ldots \ldots$ & 1 & 0.14 & 8 & 0.20 & 35 & $\mathrm{NH}_{4}$ & 0.5 & 100 & & & \\
\hline
\end{tabular}

a Iron plating bath. Contained no tungsten.

b Bath contained $\left(\mathrm{NH}_{4}\right)_{2} \mathrm{SO}_{4}, 100 \mathrm{~g} /$ liter.
- $3 \mathrm{amp} / \mathrm{dm}^{2}$.

d Bath contained $\left(\mathrm{NH}_{4}\right)_{2} \mathrm{SO}_{4}, 300 \mathrm{~g}$ /liter. 
tions were entirely converted to ferric and were difficult to reduce again. One advantage of the ferrous solution is that the cathode efficiencies are higher and the yields are greater for the same cathode efficiency. Deposits can be obtained at lower current densities in the ferrous solution than in the ferric, in which the current density usually must be at least $5 \mathrm{amp} / \mathrm{dm} .^{2}$

Iron or tungsten anodes may be used. Neither was entirely satisfactory, because they tended to become passive unless either a large excess of citrate was present, or a low anode current density was used.

\section{Electrodeposition of Ternary Alloys of Tungsten}

Some ternary alloys containing nickel, cobalt, and tungsten; and iron, cobalt, and tungsten, were deposited to demonstrate that the process is feasible, but no detailed study of their deposition or properties was made. The data given in table 11

TABLE 10.-Effect of temperature on the composition of iron-tungsten alloys deposited from citrate solutions

[Each solution contained ammonium chloride, $50 \mathrm{~g} /$ liter. Current density $5 \mathrm{amp} / \mathrm{dm}^{2}$, $\mathrm{pH}$ of plating solutions 8.5.]

\begin{tabular}{|c|c|c|c|c|c|c|c|c|c|c|c|c|c|}
\hline \multirow{3}{*}{ No. } & \multicolumn{7}{|c|}{ Bath composition } & \multicolumn{3}{|c|}{ Current efficiency at- } & \multicolumn{3}{|c|}{ Tungsten in deposit at- } \\
\hline & \multirow{2}{*}{$\begin{array}{c}\mathrm{W} / \mathrm{Fe} \\
\text { (weight) }\end{array}$} & \multicolumn{2}{|c|}{ Ferric } & \multicolumn{2}{|c|}{ W } & \multicolumn{2}{|c|}{$\begin{array}{l}\text { Sodium citrate } \\
\text { concentration }\end{array}$} & \multirow{2}{*}{$50^{\circ} \mathrm{C}$} & \multirow{2}{*}{$70^{\circ} \mathrm{C}$} & \multirow{2}{*}{$90^{\circ} \mathrm{C}$} & \multirow{2}{*}{$50^{\circ} \mathrm{C}$} & \multirow{2}{*}{$70^{\circ} \mathrm{C}$} & \multirow{2}{*}{$90^{\circ} \mathrm{C}$} \\
\hline & & Molarity & $\mathrm{g} /$ liter & Molarity & $\mathrm{g} /$ liter & Molarity & $\mathrm{g} /$ liter & & & & & & \\
\hline $1 \ldots \ldots$ & 2 & 0.29 & 16 & 0.20 & 35 & 0.30 & 100 & $\begin{array}{r}\text {;Percent } \\
29\end{array}$ & $\begin{array}{r}\text { Percent } \\
48\end{array}$ & $\begin{array}{r}\text { Percent } \\
43\end{array}$ & $\begin{array}{r}\text { Percent } \\
37\end{array}$ & $\begin{array}{r}\text { Percent } \\
41\end{array}$ & $\begin{array}{l}\text { Percent } \\
47\end{array}$ \\
\hline $2 \ldots$ & 3 & .21 & 12 & 20 & 35 & .30 & 100 & 19 & 37 & 38 & 41 & 52 & 46 \\
\hline 3 & 3.5 & .14 & 8 & .15 & 28 & .30 & 100 & 34 & 44 & 47 & 48 & 45 & 50 \\
\hline 4 & 4.5 & .14 & 8 & .20 & 35 & .30 & 100 & & 43 & 58 & & 46 & 50 \\
\hline $5, \ldots \ldots \ldots$ & 6. 0 & .11 & 6 & .20 & 35 & .30 & 100 & $\ldots$ & 55 & 41 & & 46 & 51 \\
\hline $6 \ldots$ & 9.0 & .07 & 4 & .20 & 35 & .30 & 100 & 11 & 38 & 29 & 61 & 53 & 50 \\
\hline \multirow[t]{2}{*}{$7 \ldots \ldots$} & 9.0 & .14 & 8 & .40 & 72 & .30 & 100 & 26 & & 42 & 43 & -.. & 51 \\
\hline & & & & & & , & Avg. & 24 & 44 & 42 & 46 & 47 & 50 \\
\hline $8 \ldots$ & 2.0 & .57 & 32 & .40 & 70 & .60 & 200 & - n. & 28 & 15 & $\ldots$ & 47 & 40 \\
\hline$y \ldots \ldots \ldots$ & 4.5 & .14 & 8 & .20 & 35 & .20 & 70 & - & 23 & 27 & & 53 & 47 \\
\hline $10 \ldots$ & 9.0 & .14 & 8 & .40 & 70 & .60 & 200 & - & 25 & 23 & - & 49 & 50 \\
\hline
\end{tabular}

TABLE 11.-Electrodeposition of ternary alloys of tungsten with the iron group metals from citrate solutions

[Each solution contained additional ammonium salts, $50 \mathrm{~g} /$ liter. Baths were operated at a pH of 8.5 to 9.0 and a temperature above $90^{\circ} \mathrm{C}$.]

\begin{tabular}{|c|c|c|c|c|c|c|c|c|c|c|c|c|c|c|c|c|c|c|}
\hline \multirow{4}{*}{ No. } & \multicolumn{12}{|c|}{ Bath composition } & \multirow{4}{*}{$\begin{array}{l}\text { Current } \\
\text { density }\end{array}$} & \multirow{4}{*}{$\begin{array}{l}\text { Cur- } \\
\text { rent ef- } \\
\text { ficiency }\end{array}$} & \multicolumn{4}{|c|}{ Composition of deposit } \\
\hline & \multirow{3}{*}{$\begin{array}{c}\mathrm{W} / \mathrm{Fe}+\mathrm{Ni} \\
+\mathrm{Co} \\
\text { (weight) }\end{array}$} & \multicolumn{2}{|c|}{ Co } & \multicolumn{2}{|c|}{$\mathrm{Ni}$} & \multicolumn{2}{|c|}{$\mathrm{Fe}$} & \multicolumn{2}{|c|}{ W } & \multicolumn{3}{|c|}{ Citrate } & & & & & & \\
\hline & & \multirow{2}{*}{$\begin{array}{l}\text { Molar- } \\
\text { ity }\end{array}$} & \multirow{2}{*}{$\mathrm{g} /$ liter } & \multirow{2}{*}{$\begin{array}{c}\text { Molar- } \\
\text { ity }\end{array}$} & \multirow{2}{*}{$\mathrm{g} /$ liter } & \multirow{2}{*}{$\begin{array}{c}\text { Molar- } \\
\text { ity }\end{array}$} & \multirow{2}{*}{ g/liter } & \multirow{2}{*}{$\begin{array}{c}\text { Molar- } \\
\text { ity }\end{array}$} & \multirow{2}{*}{$\mathrm{g} /$ liter } & \multirow{2}{*}{ Type } & \multicolumn{2}{|c|}{ Concentration } & & & & 1VI & & \\
\hline & & & & & & & & & & & Molarity & $\mathrm{g} /$ liter & & & & & & \\
\hline
\end{tabular}

$\mathrm{Ni}-\mathrm{Co}_{0}-\mathrm{W}$

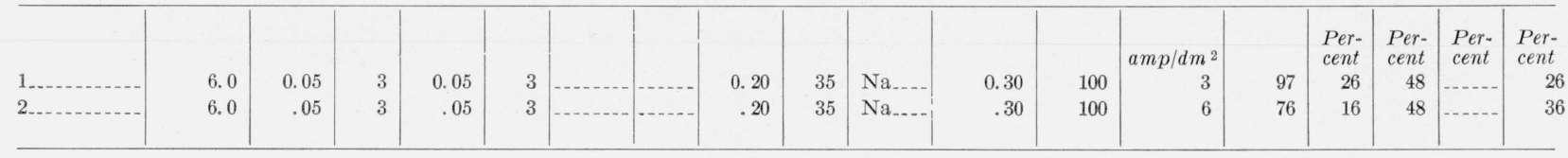

Co-W-Fe

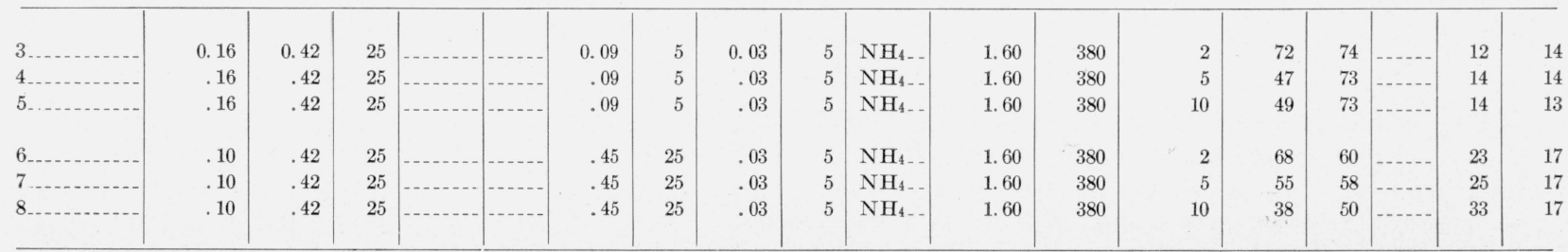


for the iron-cobalt-tungsten alloys show that the tungsten content of the deposit is lower than if a binary alloy had been deposited. For exmaple, a solution containing iron and tungsten would have yielded a deposit containing about 50 percent of tungsten, and one containing cobalt and tungsten a deposit containing about 25 percent of tungsten, but the ternary alloy contained from 14 to 17 percent of tungsten. Sykes [24] has shown that a metallurgical cobalt-iron-tungsten alloy containing 50 percent of $\mathrm{Fe}, 30$ percent of $\mathrm{Co}$, and 20 percent of $\mathrm{W}$ has a better hot-hardness than other compositions. The electrodeposition of such a ternary alloy may be of interest.

\section{Defects of Deposits}

The Rochelle salt and the citrate baths generally operated satisfactorily, but occasionally pitting and misplating (that is incomplete coverage of a surface) occurred from no known cause and no effective remedy was found. It was difficult to study these defects because the conditions could not be produced at will. The misplating was most likely to occur in the concentrated baths when low current densities were used. It could be almost entirely prevented by first coating the object with a cobalt strike and using an initially high current density in the alloy bath. The pitting of deposits could be lessened by moving of the object and by filtering of the solution through activated charcoal. Plating solutions containing high concentrations of hydroxyacetates were especially prone to pit. This is regrettable because this acid is the most economical for preparing the solutions for plating tungsten alloys.

\section{Stripping Defective Deposits From Steel}

Defective deposits of cobalt-tungsten alloy were stripped from steel anodically in either a cyanide solution or an ammoniacal solution of ammonium nitrate. The latter solution was almost saturated with ammonium nitrate and contained 100 to $200 \mathrm{ml}$ of ammonium hydroxide per liter. The anodic current density was about $8 \mathrm{amp} / \mathrm{dm}^{2}$. Although the stripping action in this bath was rapid, after the solution was used for a time, it tended to attack carbon steels. The cyanide solution contained sodium cyanide, $200 \mathrm{~g} /$ /liter and the current density ranged from 1 to $5 \mathrm{amp} / \mathrm{dm}^{2}$. At the lower current density, the metal was active and stripped with good efficiency, but at the higher current densities, the action was slower. The cyanide solution is more reliable than the nitrate when it is important not to injure the steel. Nickel-tungsten alloys can be anodically stripped from steel with a hot saturated solution of sodium or ammonium nitrate, in the same manner that nickel is stripped. The required current density is about $25 \mathrm{amp} / \mathrm{dm}^{2}$.

To strip coatings from steel for analysis, a solution consisting of 2 volumes of fuming nitric acid and 1 volume of hydrofluoric acid is used, which rapidly dissolves the coating with very slight attack of the steel. The solution must be warmed on the steam bath until the reaction begins.

\section{Analysis of Alloy Deposits and Plating Solutions}

No high degree of accuracy was attempted in the analyses, as the results of the plating experiments were not highly reproducible. It was usually considered satisfactory to know the concentration of each metal in the plating solution within about 5 percent of its content, and the composition of the deposits to the nearest percent.

In analyzing for tungsten, the deposits were dissolved in nitric and hydrofluoric acid in the manner indicated above, and the solution was evaporated to fumes of sulfuric acid. The tungsten was precipitated with either brucine or cinchonine. The presence of the iron group metals did not interfere with the tungsten determination.

The analysis of the baths was a little more troublesome because of the presence of the organic matter. The tungsten was determined by boiling a portion of the solution with nitric acid and filtering off the tungsten, usually without the addition of an alkaloid, unless more precise results were desired. A higher degree of accuracy was obtained by destroying the organic constituents of the solutions before precipitating the tungsten.

A cyanide titration was occasionally used for determining cobalt [12] in the plating solutions. It was necessary first to destroy the hydroxy acid, as otherwise low results were obtained. The complete oxidation of the organic acid was indicated by no further charring when fumed with sulfuric acid. Oxidation did not proceed very fast with nitric and sulfuric acid. Better results were obtained by treating with potassium periodate and sulfuric acid and heating to fuming. With citrates, hot concentrated sulfuric acid and per- 
sulfates were effective. Even after the organic acid was destroyed, the titration of cobalt gave results that were about 10 percent too high. For this reason a colorimetric method based on the blue color developed with thiocyanates and acetone was used. By using a calibration curve on a spectrophotometer, this method was made very rapid, and the results were correct within about 5 percent. The reagent used for developing the color contained $200 \mathrm{~g}$ of ammonium thiocyanate, $20 \mathrm{~g}$ of potassium pyrophosphate (for decolorizing iron compounds) and $50 \mathrm{ml}$ of acetic acid, all dissolved in $500 \mathrm{ml}$ of water and diluted with acetone to 1 liter.

Attempts were made to devise a colorimetric method for cobalt that would make use of the purple color developed in cobalt solutions by hydroxy acids. Such a method would permit the plating solutions to be analyzed directly, without the large dilutions required when sensitive colorimetric reagents are used. However, it was not found possible to secure reproducible colors, either on the acid or on the alkaline side. Ammoniacal cobalt solutions containing a hydroxy acid absorb oxygen and change color on standing.

The analysis of the nickel-tungsten solutions for nickel was simpler than the procedures required for cobalt. The nickel could be determined with the well known cyanide titration with sufficient accuracy, and the organic material did not interfere.

The total iron content of the iron-tungsten baths can be determined by any one of the standard methods, after the organic material is destroyed. No entirely satisfactory procedure has been worked out to determine both ferrous and ferric iron in a plating solution after it had been in operation. Colorimetric methods for either form of iron were not suitable, because in these dilute solutions the ferrous iron tended to oxidize. A reducing agent could not be added to stabilize the ferrous iron without danger of reducing some of the ferric iron. One method for determining ferrous iron is to titrate with permanganate after the sample has been acidified with acetic acid. The endpoint was not sharp, but higher acidities permitted oxidation of the organic acid. More accurate and rapid methods of analysis are needed.

The only hydroxy acid that was determined regularly was tartaric acid, which was done by oxida- tion with potassium permanganate, previously standardized with known amounts of tartrate.

\section{Properties of Electrodeposited Tungsten Alloys}

\section{Criteria of Satisfactory Deposits}

The properties of deposits that may be considered as commercially satisfactory may be summarized qualitatively as follows. The deposits should be mechanically sound, that is, a deposit not more than a tenth of a millimeter thick should hold together when the base metal is dissolved away, and under the microscope the deposit should not reveal any cracks or pores. Deposits up to a millimeter or more in thickness should be obtainable without many nodules. The deposits should not contain large amounts of inclusions, particularly oxides. The content of oxygen in ordinary electrodeposited chromium, that is, about 0.3 percent, may be considered an upper limit that can be present in deposits for engineering uses. Commercial electrodeposits of other metals contain less than 0.1 percent of oxygen. Of the many published processes for depositing metals or alloys, few yield coatings useful for engineering applications. Studies on the electrodepositon of alloys have centered largely around the production and analysis of thin deposits and their variations with changes of plating conditions. No evidence has usually been offered to show whether the alloys are sound or whether thick deposits could be obtained.

The above criteria are met substantially by the cobalt-tungsten alloys and the nickel-tungsten alloys but not yet by the iron-tungsten alloys. The physical properties of the latter are inferior, except in hardness, to the former two alloys. The iron-tungsten deposits are usually weak and brittle and may crack or fall apart when the base metal is dissolved.

\section{Appearance of Tungsten Alloys}

Deposits up to $0.1 \mathrm{~mm}$ thick are smooth and range in color from dark grey to bright. The cobalt-tungsten alloys have almost the same grey color as electrodeposited cobalt. The nickel alloys may vary from semibright to dark grey, the latter being obtained from the more concentrated tartrate plating solutions. The iron alloys vary from grey to bright, similar to chromium. The ap- 


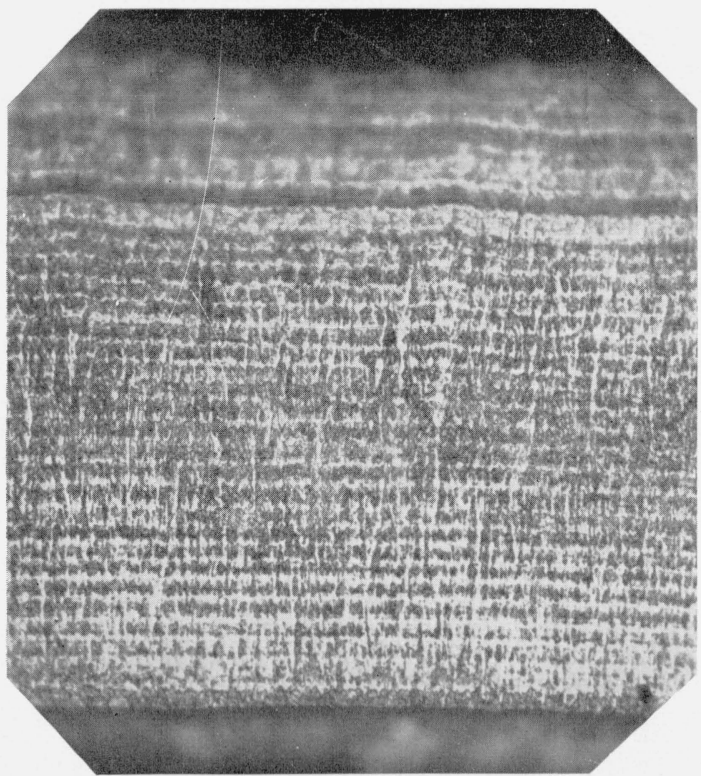

Figure 4. Laminations in a cobalt-tungsten deposit, containing 23 percent of tungsten.

$\mathrm{X} 250$

pearance of the deposits may depend to some extent on the presence of small amounts of impurities in the bath.

\section{Structure of Alloys}

Microstructure.-As deposited, the alloys usually show laminations running parallel to the base metal, even though the current was not

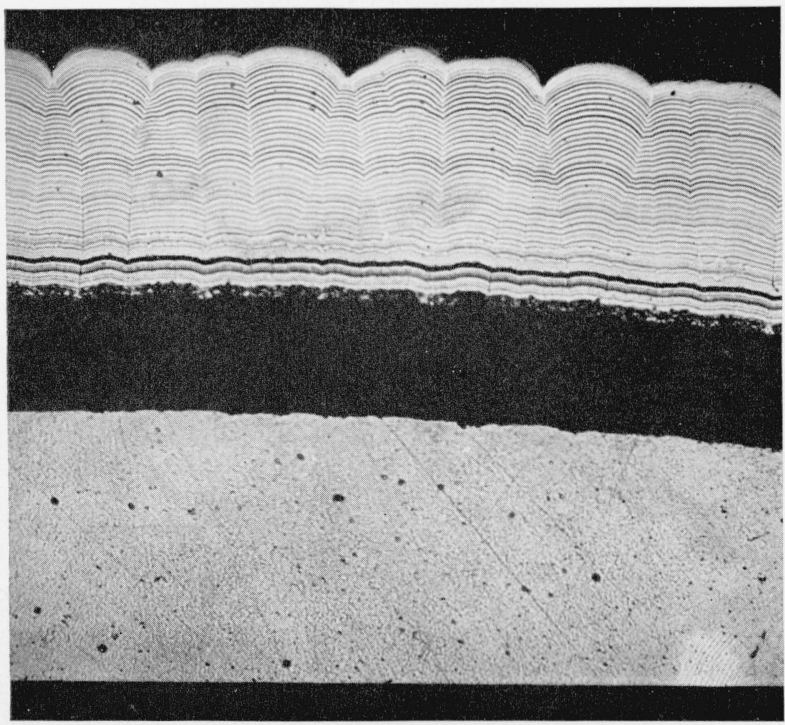

Figure 5. Laminations in an iron-tungsten deposit, containing 48 percent of tungsten.

$\mathrm{X} 250$. interrupted. In this respect the deposits resemble some "bright nickel" deposits. The iron alloys show this lamination to the greatest degree, and occasionally the adhesion is poor between the layers. Some of the cobalt-tungsten alloys show also a columnar structure perpendicular to the surface, similar to that of electrodeposited nickel or cobalt. Photomicrographs of a cobalt-tungsten and an iron-tungsten alloy deposit are shown in figures $4,5,6$. When plated under unfavorable conditions, such as too high a current density, the alloy may contain voids and cracks. On heating above $1,000^{\circ} \mathrm{C}$, the laminations disappear and a grain structure is developed (see fig. 7,8 ).

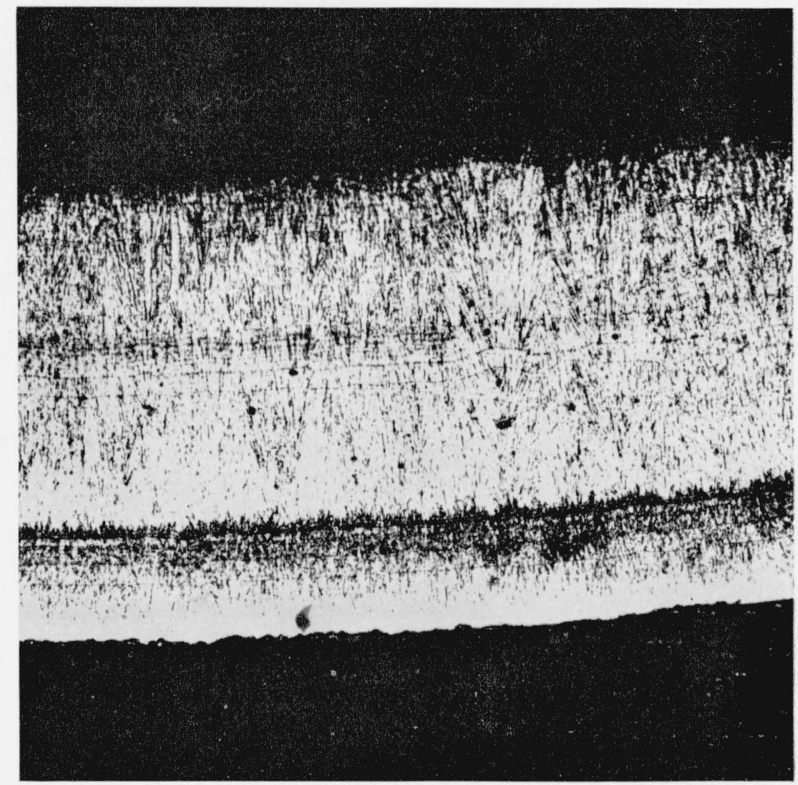

Figure 6. Cobalt-tungsten alloy (25 percent tungsten) showing laminations parallel to the base metal and a columnar structure perpendicular to the base metal. $\mathrm{X} 100$.

Crystal Structure.-Previous X-ray studies of electrodeposited alloys have shown that they are generally composed of the same phases as those present in the comparable thermally prepared alloys. This was not borne out by X-ray studies of the electrodeposited cobalt-tungsten and irontungsten alloys. These appear to be solid solutions, although according to the equilibrium diagrams [10], a fair proportion of an intermetallic compound should be present as another phase. The importance of this structure will be discussed in connection with the precipitationhardening of the alloys. 


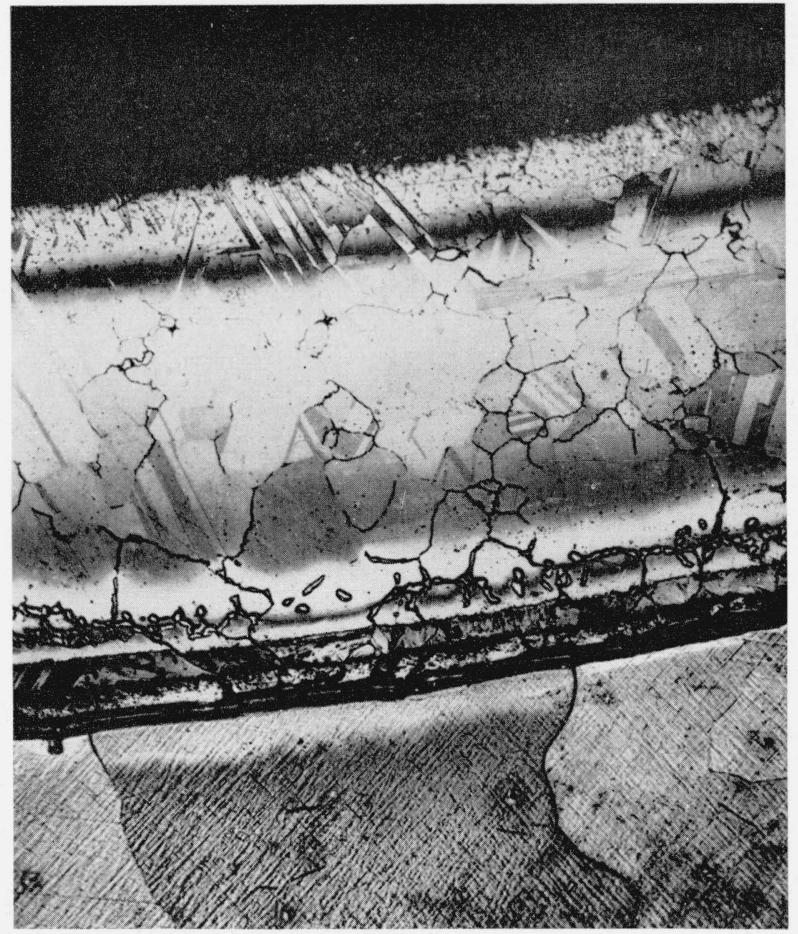

Figure 7. Cobalt-tungsten alloy (also shown in fig. 6) after being heated to $1,300^{\circ} \mathrm{C}$ for $15 \mathrm{hr}$.

Note disappearance of the laminations and the appearance of grains. X100.

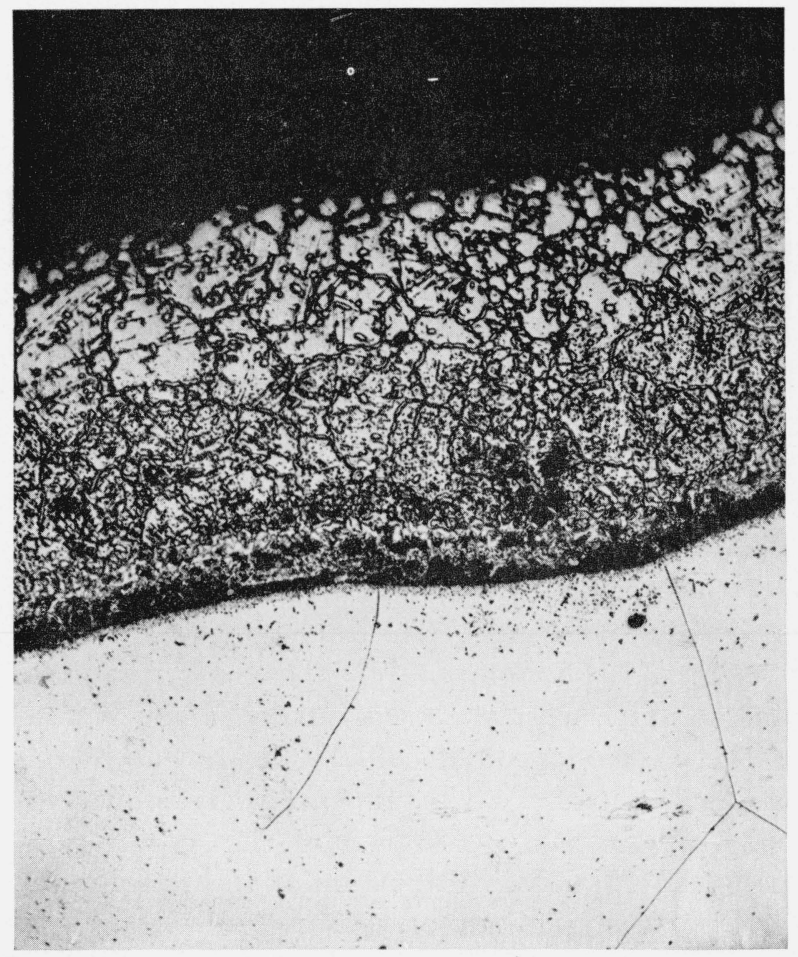

Figure 8. Cobalt-tungsten alloy (also shown in figs. 6 and 7) after being precipitation-hardened at $800^{\circ} \mathrm{C}$.

The specimen has been overaged. X100.

\section{Physical Properties}

Hardness.-The hardness of the electrodeposited tungsten alloys is perhaps their most interesting property. Not only are they relatively hard as obtained from the bath, but they also increase in hardness when subjected to suitable heat-treatments, as shown in table 12 . The hardness

TABLE 12.-Hardness of electrodeposited tungsten alloys a

\begin{tabular}{|c|c|c|c|c|c|}
\hline \multirow{2}{*}{ No. } & \multirow{2}{*}{ Type of bath } & \multirow{2}{*}{$\begin{array}{c}\text { Tungsten } \\
\text { in } \\
\text { deposit }\end{array}$} & \multicolumn{3}{|c|}{ Vickers hardness } \\
\hline & & & Initial & $\begin{array}{l}1 \mathrm{hr}, \\
600^{\circ} \mathrm{C}\end{array}$ & Change \\
\hline
\end{tabular}

COBALT-TUNGSTEN

\begin{tabular}{|c|c|c|c|c|c|}
\hline & & Percent & & & \\
\hline $\begin{array}{l}1 \\
2\end{array}$ & $\begin{array}{l}\text { Standard cobalt } \\
\text { Gluconate }\end{array}$ & 7 & $\begin{array}{l}330 \\
420\end{array}$ & $\begin{array}{l}250 \\
358\end{array}$ & $\begin{array}{l}-80 \\
-62\end{array}$ \\
\hline 3 & do & 2 & $\begin{array}{l}420 \\
341\end{array}$ & $\begin{array}{l}358 \\
284\end{array}$ & $\begin{array}{l}-02 \\
-57\end{array}$ \\
\hline 4 & .... do ........... & 2 & 380 & 245 & -135 \\
\hline 5 & ..... do & 4 & 348 & 294 & -54 \\
\hline b 6 & 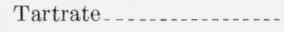 & 4 & 389 & 391 & -2 \\
\hline 7 & Gluconate & 4 & 426 & 459 & 33 \\
\hline 8 & _._. do & 5 & 452 & 555 & 103 \\
\hline 9 & Tartrate ............. & 8 & 461 & 467 & 6 \\
\hline 10 & Ammonium sulfate & 9 & 425 & 413 & -12 \\
\hline 11 & Tartrate & 9 & 460 & 480 & 20 \\
\hline 12 & _ _ do _ _ _ _ _ n & 9 & 381 & 469 & 88 \\
\hline 13 & ..... do . . . & 10 & 435 & 528 & 93 \\
\hline 14 & _..._do do....... & 10 & 440 & 543 & 103 \\
\hline 15 & Gluconate...... & 11 & 486 & 566 & 80 \\
\hline 16 & Tartrate $\ldots . . . .$. & 12 & 509 & 654 & 145 \\
\hline 17 & _. do & 12 & 415 & 558 & 143 \\
\hline 18 & _._. do . . . & 14 & 380 & 487 & 107 \\
\hline 19 & 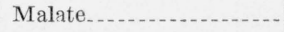 & 15 & 450 & 578 & 128 \\
\hline 20 & Tartrate ...... & 15 & 458 & 645 & 187 \\
\hline 21 & ..... do & 15 & 392 & 586 & 194 \\
\hline 22 & do & 16 & 465 & 693 & 228 \\
\hline 23 & Malate ........ & 16 & 360 & 590 & 230 \\
\hline 24 & Tartrate $\ldots . . .$. & 17 & 485 & 695 & 210 \\
\hline 25 & do & 18 & 422 & 516 & 94 \\
\hline 26 & do $\ldots \ldots$ & 18 & 487 & 613 & 126 \\
\hline 27 & _.... do & 19 & 517 & 750 & 233 \\
\hline 28 & _._. do & 20 & 500 & 702 & 202 \\
\hline 29 & _. do & 21 & 396 & 528 & 132 \\
\hline 30 & Hydroxyacetate.... & 21 & 460 & & -... \\
\hline 31 & Citrate $\ldots . . . . .$. & 22 & 340 & 370 & 30 \\
\hline 32 & Tartrate .......... & 24 & 458 & 684 & 226 \\
\hline 33 & Malate_........... & 25 & 455 & 630 & 175 \\
\hline 34 & Tartrate & 25 & 524 & 747 & 223 \\
\hline 35 & Hydroxyacetate....... & 25 & 480 & & \\
\hline 36 & Tartrate & 26 & 704 & 988 & 284 \\
\hline 37 & ..... do & 31 & 470 & 757 & 287 \\
\hline 38 & $\ldots$..... do & 33 & 615 & 810 & 195 \\
\hline 39 & _... do _ _ _ & 35 & 684 & 824 & 140 \\
\hline 40 & _. do & 36 & 535 & 710 & 175 \\
\hline 41 & Citrate & 53 & 564 & 1,035 & 471 \\
\hline 42 & do & 57 & 624 & 907 & 283 \\
\hline
\end{tabular}

See footnotes at end of table. 
TABLE 12.-Hardness of electrodeposited tungsten alloys -Continued

\begin{tabular}{|c|c|c|c|c|c|}
\hline \multirow{2}{*}{ No. } & \multirow{2}{*}{ Type of bath } & \multirow{2}{*}{$\begin{array}{c}\text { Tungsten } \\
\text { in } \\
\text { deposit }\end{array}$} & \multicolumn{3}{|c|}{ Vickers hardness } \\
\hline & & & Initial & $\begin{array}{c}1 \mathrm{hr}, \\
600^{\circ} \mathrm{C}\end{array}$ & Change \\
\hline
\end{tabular}

NICKEL-TUNGSTEN

\begin{tabular}{|c|c|c|c|c|c|}
\hline 1 & Hydroxyacetate............. & $\begin{array}{r}\text { Percent } \\
1\end{array}$ & 513 & 258 & -255 \\
\hline 2 & do & 2 & 380 & 445 & 65 \\
\hline 3 & do & 3 & 340 & 415 & 75 \\
\hline 4 & do & 4 & 507 & 370 & -137 \\
\hline 5 & Glycinate. & 5 & 345 & 268 & -77 \\
\hline 6 & Hydroxyacetate & 5 & 410 & 450 & 40 \\
\hline 7 & Tartrate & 7 & 608 & 378 & -230 \\
\hline 8 & Citrate & 9 & 621 & 355 & -266 \\
\hline 9 & Hydroxyacetate & 10 & 370 & 420 & 50 \\
\hline 10 & Glycinate & 11 & 600 & 600 & 0 \\
\hline 11 & Citrate............. & 13 & 473 & 312 & -161 \\
\hline 12 & 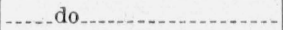 & 14 & 508 & 867 & 359 \\
\hline - 13 & Tartrate & 14 & 498 & 344 & -154 \\
\hline 14 & Citrate & 17 & 591 & 744 & 153 \\
\hline 15 & do do & 25 & 662 & 783 & 121 \\
\hline 16 & do do & 25 & 532 & 379 & -153 \\
\hline 17 & _ do & 26 & 642 & 653 & 11 \\
\hline 18 & _._. do & 29 & 623 & 645 & 22 \\
\hline 19 & do & 30 & 597 & 750 & 153 \\
\hline 20 & do & 31 & 648 & 805 & 157 \\
\hline 21 & do & 31 & 611 & 517 & -94 \\
\hline 22 & _. do & 33 & 643 & 772 & 129 \\
\hline 23 & _._. do & 36 & 693 & 752 & 59 \\
\hline
\end{tabular}

IRON-TUNGSTEN

\begin{tabular}{|c|c|c|c|c|c|}
\hline 1 & Citrate..... & 48 & 960 & 1,200 & 240 \\
\hline 2 & _ do do _ & 49 & 720 & 920 & 200 \\
\hline 3 & _. do do & 51 & 890 & 1,400 & 510 \\
\hline 4 & ..... do & 52 & 750 & 1,350 & 600 \\
\hline 5 & _ do do & 52 & 960 & 1,120 & 160 \\
\hline d 6 & ...... do & 53 & 1,010 & 1,400 & 390 \\
\hline 7 & ...... do_.. & 53 & 1,340 & 1,020 & -320 \\
\hline 8 & ..... do & 54 & 800 & 1,230 & 430 \\
\hline 9 & do do & 56 & 790 & 1,330 & 540 \\
\hline 10 & _. do do & 56 & 970 & 1,460 & 490 \\
\hline 11 & do do & 56 & 840 & 1,260 & 420 \\
\hline
\end{tabular}

- Deposits having the same composition are not duplicates, but were plated from different solutions under different conditions.

b In this group, Nos, 6 to 42 , the hardness increased as a result of heating.

- In this group, Nos. 13 to 23 , the hardness increased as a result of heating.

d Plated at $70^{\circ} \mathrm{C}$.

measurements were made either with an Eberbach microhardness tester, which uses a Vickers diamond, or with a Knoop tester, on a polished cross section of the coating, which was $0.05 \mathrm{~mm}$ or more in thickness. All hardness readings were converted to the Vickers scale.

The initial hardnesses of the cobalt and the nickel alloys were about the same, from 350 to 700
Vickers. On heating to $600^{\circ} \mathrm{C}$ for an hour and cooling, certain of these alloys increased in hardness by more than 100 points, probably as a result of precipitation hardening. The nickel alloys exhibited less tendency toward this increased hardening than did the cobalt alloys. The data in table 12 show that precipitation hardening occurred with cobalt-tungsten alloys containing above 5 percent of tungsten, and with nickel-tungsten alloys containing above 17 percent of tungsten. There are exceptions in both directions, however. Some alloys with a high tungsten content softened on heating and others with a low. tungsten content hardened. The increase in hardness on heating is variable and depends somewhat on the conditions of deposition as well as on the tungsten content.

The precipitation-hardening of the metallurgical nickel- and cobalt-tungsten alloys has been studied by Sykes and coworkers [11, 23, 24]. For precipitation-hardening to occur, the cobalt alloy had to contain more than 10 percent of tungsten and the nickel alloy more than 32 percent of tungsten. Precipitation-hardening occurs at lower tungsten contents with the electrodeposited alloys than with the metallurgical alloys. The maximum hardness obtainable for the metallurgical alloys by precipitation-hardening (about 500 Vickers) was less than that obtained with the electrodeposited alloys (about 700 Vickers).

The iron-tungsten alloys as deposited are considerably harder than the cobalt and nickel alloys. The hardness ranges from 700 to 900 Vickers, which is somewhat less than the hardness of bright chromium (about 900 to 1,000). After heating at $600^{\circ} \mathrm{C}$ for an hour the hardness of the iron alloy increases to from 900 to 1,400 Vickers. There seems to be no correlation of the hardness and the conditions of plating. If the hardness of the irontungsten alloy can be utilized commercially, there would be more incentive toward this development.

The effect of temperature and time of heating of the tungsten alloys on the precipitation-hardening was explored, but no thorough study was made. In figure 9 are shown the averages of the data for two cobalt-tungsten deposits. The optimum temperature for their hardening is $600^{\circ} \mathrm{C}$. Higher temperatures and longer periods of heating at these temperatures cause a softening of the deposit, although the deposits are still quite hard (450 Vickers) after an hour at $1,200^{\circ} \mathrm{C}$. A 


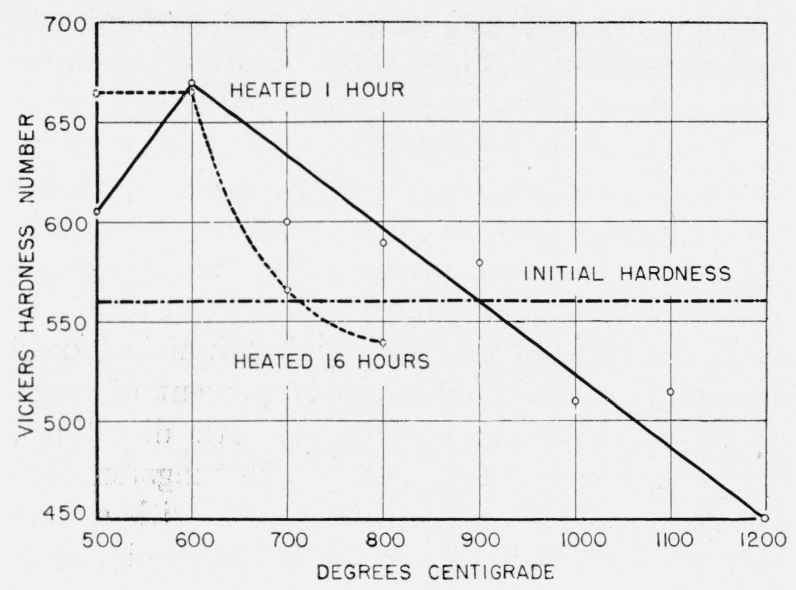

Figure 9. Hardness of cobalt-tungsten alloys after being subjected to heat treatments.

deposit containing about 25 percent of tungsten, which was heated at $1,300^{\circ} \mathrm{C}$ for 15 hours, decreased in hardness from 420 to 150 Vickers. This softened alloy was capable of being subsequently precipitation-hardened.

The optimum temperature of hardening for the nickel alloys appears to be below $600^{\circ} \mathrm{C}$, because they become ductile at this temperature. The optimum temperature for the iron-tungsten alloys with 50 percent of tungsten seems to be above $600^{\circ} \mathrm{C}$. The following results were obtained for an iron-tungsten deposit that had an initial hardness of about 780 Vickers. After heating for an hour at $600^{\circ} \mathrm{C}$, the hardness was 780 Vickers; at $800^{\circ} \mathrm{C}, 1030$ Vickers; and at $1,200^{\circ} \mathrm{C}, 990$ Vickers.

The precipitation-hardening of these alloys differentiates them from other hard electrodeposits, such as hard nickel, which owe their hardness mainly to some type of internal stress. Hard nickel undergoes a stress relief at the comparatively low temperature of $300^{\circ} \mathrm{C}$ [27] and hence is not suitable for use at high temperatures.

The detection by X-rays of only a single-phase solid solution in the cobalt- and iron-tungsten alloys is of interest, because of its bearing upon the explanation of the hardening that takes place on heating. In the usual precipitation hardening of a thermally prepared alloy, it is heated to a temperature at which a solid solution is produced and is then cooled to room temperature with the solid solution still present but not completely in equilibrium. On holding the alloy at an elevated temperature (but below the initial high temperature), a second phase precipitates from the solid solution at the grain boundaries, and causes an increased hardness of the material. If the electrodeposited alloys were in an equilibrium condition, then the second phase (which may be either a solid solution or intermetallic compound) would already be present and there would be no tendency for it to deposit from the solid solution at the grain boundaries when the alloy is heated. However, the alloy is already in the form of a solid solution as deposited, that is, in a state comparable to the unstable thermal alloys. Hence precipitation-hardening readily takes place without the usual preliminary heat treatment. The close relation between the mechanism of the hardening of electrodeposited and the thermal cobalttungsten alloys is shown by the fact that the optimum temperature of hardening is about the same for both, viz $600^{\circ} \mathrm{C}$.

This explanation of the hardening of the alloys does not suffice to explain the hardening of the nickel-tungsten alloys, as according to the phase diagram $[10,11]$, no second phase should precipitate if the content of tungsten is below 32 percent.

The formation of an intermetallic compound in the electrodeposited cobalt- and iron-tungsten alloys that had been hardened at $600^{\circ} \mathrm{C}$ could not be detected by X-rays. This does not necessarily mean that no compound has been formed, but rather, that the quantity is too small to be detected. On heating an iron-tungsten deposit to $1,200^{\circ} \mathrm{C}$, new $\mathrm{X}$-ray lines were obtained, which indicated the presence of a new phase that did not correspond very closely, however, with the lines reported for the iron-tungsten compounds, $\mathrm{Fe}_{2} \mathrm{~W}$ and $\mathrm{Fe}_{3} \mathrm{~W}_{2}$.

Hot-Hardness. - The hot-hardness (that is, the hardness at elevated temperatures) of only the cobalt-tungsten alloys was measured (through the courtesy of the Climax Molybdenum Co.). The values are given in table 13 , along with data on several other metals for comparison. The alloys with the higher tungsten contents show a good hot-hardness, comparable to that of stellite. Precipitation-hardening of the alloy (No. 8, table 13) increased its hot-hardness.

Ductility of the Alloys.- The ductility of the alloys was determined qualitatively by the permanent deformation obtained on bending a specimen. The iron alloys were brittle under all conditions of plating. The nickel and cobalt alloys had a slight ductility if they contained not over 5 
percent of tungsten, otherwise they had no apparent ductility. On heating the nickel alloys to $600^{\circ} \mathrm{C}$ or above, and the cobalt alloys above $900^{\circ} \mathrm{C}$, they become quite ductile. The temperature for this treatment of the cobalt alloys seemed rather critical, as no ductility was obtained at lower temperatures even after some hours of heating, whereas at the proper temperature for the alloy the ductility developed in a few minutes. This temperature varied somewhat with the composition of the alloy. Alloys containing up to 12 percent of tungsten could be made ductile by heating to $900^{\circ} \mathrm{C}$, but the higher-tungsten alloys required a temperature of about $1,000^{\circ} \mathrm{C}$. The temperatures required to produce ductility correspond approximately to the solid solubility line of $\mathrm{Co}_{3} \mathrm{~W}$ in the equilibrium diagram. The irontungsten alloys were still brittle after being heated to $1,200^{\circ} \mathrm{C}$.

TABLE 13.-Hot-hardness of cobalt-tungsten alloys and some other metals

\begin{tabular}{|c|c|c|c|c|}
\hline \multirow{2}{*}{ No } & \multirow{2}{*}{ Metal } & \multicolumn{3}{|c|}{$\begin{array}{l}\text { Vickers hardness } \\
\text { number at- }\end{array}$} \\
\hline & & $20^{\circ} \mathrm{C}$ & $700^{\circ} \mathrm{C}$ & $800^{\circ} \mathrm{C}$ \\
\hline 1 & Steel _. _ & 290 & 50 & 36 \\
\hline 2 & Cobalt, electrodeposited & 300 & 65 & 55 \\
\hline 3 & Cobalt-tungsten alloy, electrodeposited, $12 \% \mathrm{~W}$ & 500 & 198 & 42 \\
\hline 4 & Cobalt-tungsten alloy, electrodeposited, $15 \% \mathrm{~W}$ & 500 & 95 & 34 \\
\hline 5 & Cobalt-tungsten alloy, electrodeposited, $20 \% \mathrm{~W}$ & 540 & 210 & 82 \\
\hline 6 & Cobalt-tungsten alloy, electrodeposited, $23 \% \mathrm{~W}$ a & 510 & 150 & 53 \\
\hline 7 & Do b & 560 & 160 & 64 \\
\hline 8 & Do ${ }^{c}$ & 610 & 300 & 180 \\
\hline 9 & Cobalt-tungsten alloy, electrodeposited, $25 \% \mathrm{~W}$ & 520 & 370 & 220 \\
\hline 10 & Cobalt-tungsten alloy, cast, $7 \% \mathrm{~W}$ & 340 & 195 & 110 \\
\hline 11 & Cobalt-tungsten alloy, cast, $12 \% \mathrm{~W}$ & 510 & 220 & 105 \\
\hline 12 & Cobalt-tungsten alloy, cast, $15 \% \mathrm{~W}$ & -..... & 190 & 105 \\
\hline 13 & Cobalt-tungsten alloy, cast, $25 \% \mathrm{~W}$ & ...... & ....... & 200 \\
\hline 14 & Stellite-_- & 470 & 300 & ..... \\
\hline 15 & Do & 315 & 200 & 175 \\
\hline
\end{tabular}

a Alloy as deposited.

b Alloy heated to $1,000^{\circ} \mathrm{C}$ for $1 \mathrm{hr}$ and $850^{\circ} \mathrm{C}$ for $1 \mathrm{hr}$.

- Alloy heated to $1,200^{\circ} \mathrm{C}$ for $1 \mathrm{hr}$. Precipitation hardened for $100 \mathrm{hr}$ at $600^{\circ} \mathrm{C}$.

Thermal Properties. - The dimensional changes on heating were determined only with the cobalttungsten alloys. Our interest in this measurement arose from the fact that when deposits 0.25 millimeter thick on steel were heated above $900^{\circ} \mathrm{C}$ to render them ductile, cracking would occasionally occur. To measure the dimensional changes that occurred on heating, a tubular specimen of the alloy, from which the base metal had been stripped, was heated and then cooled. The change in length of the tube as a result of the treatment was measured with a micrometer.

Dimensional changes as a result of heating seem to be characteristic of some electrodeposits. The contraction of chromium to the extent of about 1 percent when heated is well known Nickel deposited from strong chloride solution (unpublished work) shows permanent expansion of about 3 percent when heated The data in table 14 show that the cobalt-tungsten alloy may either expand or contract as a result of heating, and the effect does not seem to be highly reproducible As the expansions seem to occur chiefly with alloys that are plated from solutions with high concentrations of the organic constituent and of cobalt (1,2, 11 to 14 , table 14 ), they may be related to the presence of inclusions.

Coefficient of Thermal Expansion.-The coefficient of thermal expansion was measured at elevated temperatures to determine at what temperatures permanent dimensional changes occurred. The coefficient of thermal expansion of electrodeposited cobalt was measured as a basis of comparison. The specimens of alloy and cobalt used for these measurements were tubes about $30 \mathrm{~cm}$ long and $5 \mathrm{~mm}$ in diameter, which were obtained in the usual way by stripping out the copper tube on which the metal had been deposited. The data are shown in figure 10 . The cobalt showed the presence of a transition point as $425^{\circ} \mathrm{C}$, which has been reported previously for metallurgical cobalt [26]. The alloy specimens showed a fairly linear change in length with temperature until a temperature of about $800^{\circ} \mathrm{C}$ was reached, and from this point on, a rapid expansion in length was noted, the coefficient of expansion nearly quintupling during the next 150 degrees. On cooling, the original curve was not retraced, and at room temperature a permanent expansion was retained corresponding to the rapid expansion above $800^{\circ}$ C. The average coefficient of thermal expansion for the range $0^{\circ}$ to $900^{\circ} \mathrm{C}$, as determined from the cooling curve, was $13.8 \times 10^{-6}$ for the alloy, as compared with $14.5 \times 10^{-6}$ for the electrodeposited cobalt.

Density.-The densities of the alloys were measured by the loss-in-weight method, using symmetrical tetrabromoethane as the liquid. Occasionally, the density of an alloy was measured as a means of rapidly determining its approximate composition. This can be done, because the 


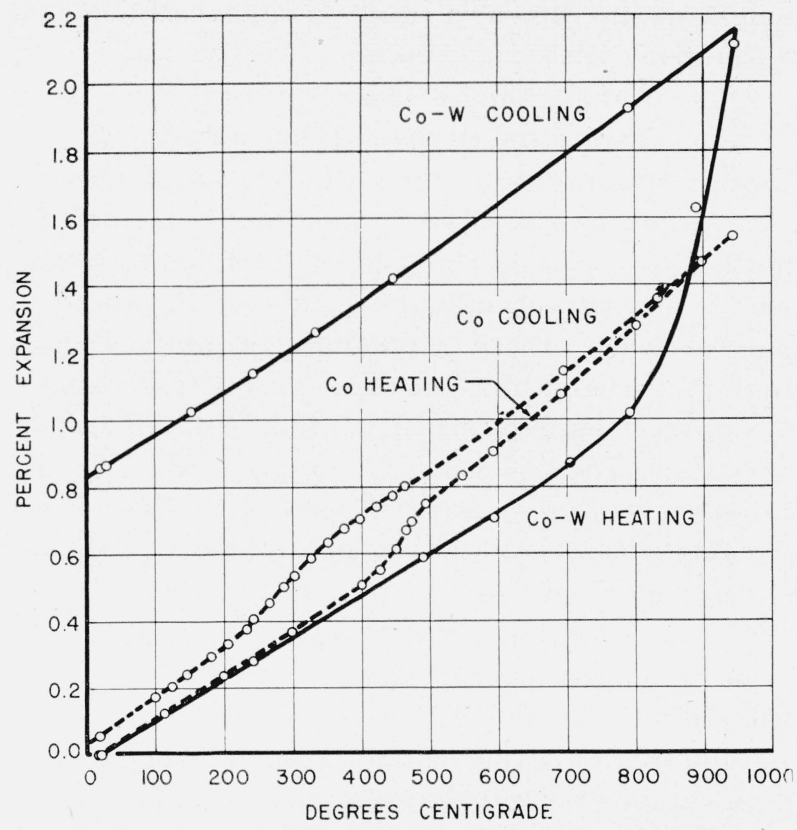

FIGURE 10.-Thermal expansion of electrodeposited cobalt and cobalt-tungsten alloy, containing 10 percent of tungsten.

Note the transition point at about $425^{\circ} \mathrm{C}$ shown by the curve for cobalt, and the increase in thermal expansion above $800^{\circ} \mathrm{C}$ shown by the curve for the cobalt-tungsten alloy. densities of the iron group metals and of tungsten differ so widely. Figure 11 shows the calculated curve of percent tungsten with respect to density, for the cobalt or nickel-tungsten alloys (assuming no volume change to have occurred in the formation of the alloy). The circles show the agreement obtained between the percent tungsten obtained by analysis and from the measurement of density. The agreement was usually about 1 percent, although occasionally larger errors occurred.

Mechanical Properties.-A few rough measurements of tensile strength were made of some nickeltungsten alloys containing about 20 percent tungsten. The tensile strength varied from $78 \mathrm{~kg} / \mathrm{mm}^{2}$ to $110 \mathrm{~kg} / \mathrm{mm}^{2}$. These values may be low, because in some tests specimens fractued at the grips. Electrodeposited cobalt was found to have a tensile strength of about $55 \mathrm{~kg} / \mathrm{mm}^{2}$.

Young's Modulus.-Young's modulus was determined by the flexure of a tube under load. Several results for Young's modulus are given in table 15. With the exception of one result for a nickel alloy that is low and may be the result of a defective specimen, the moduli for the three alloys

TABLE 14. Change in length of tubes of electrodeposited cobalt-tungsten alloy after heating 1 hr at $1.000^{\circ} \mathrm{C}$

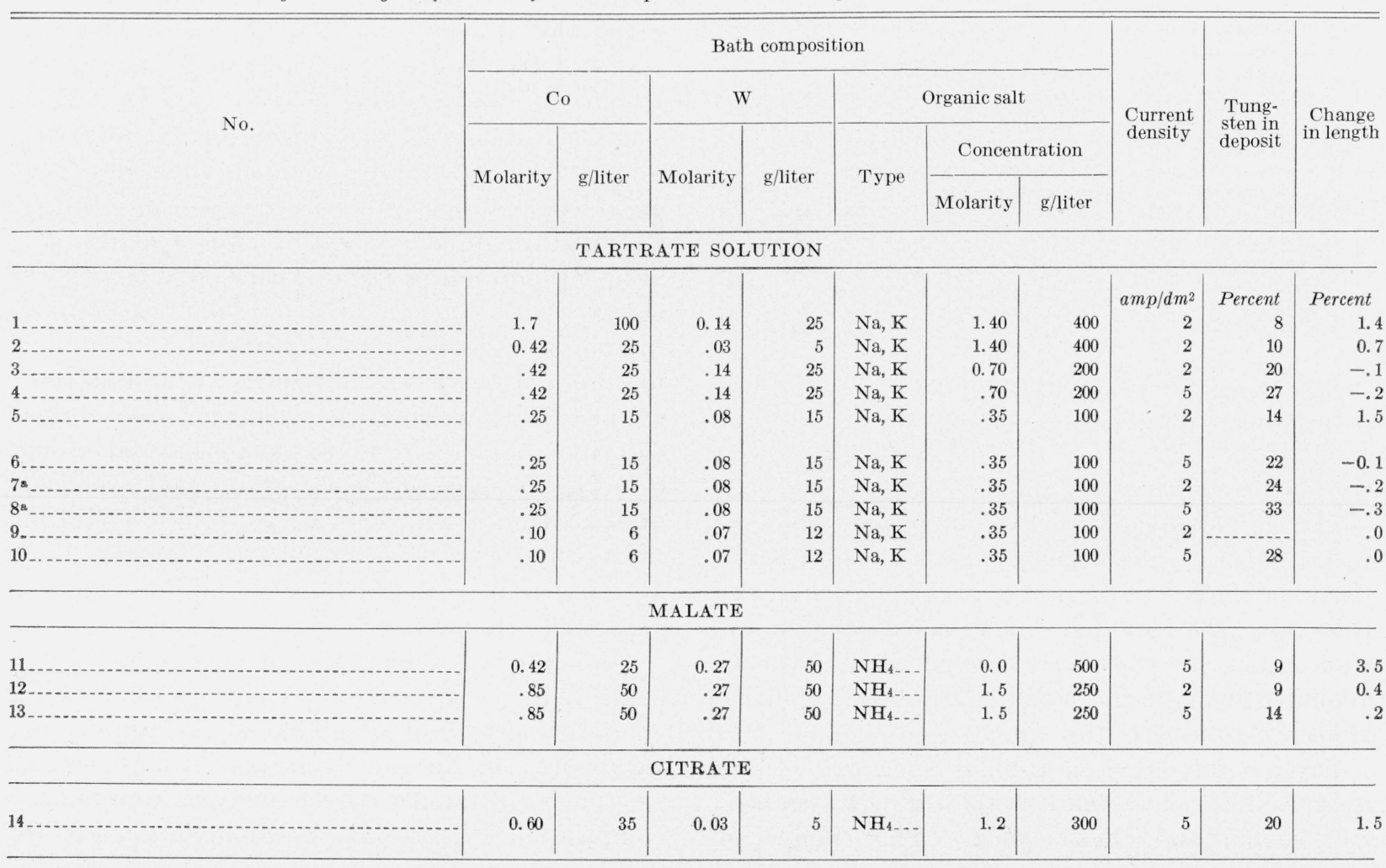

2 Solution contained ammonium sulfate, $300 \mathrm{~g} /$ liter. 


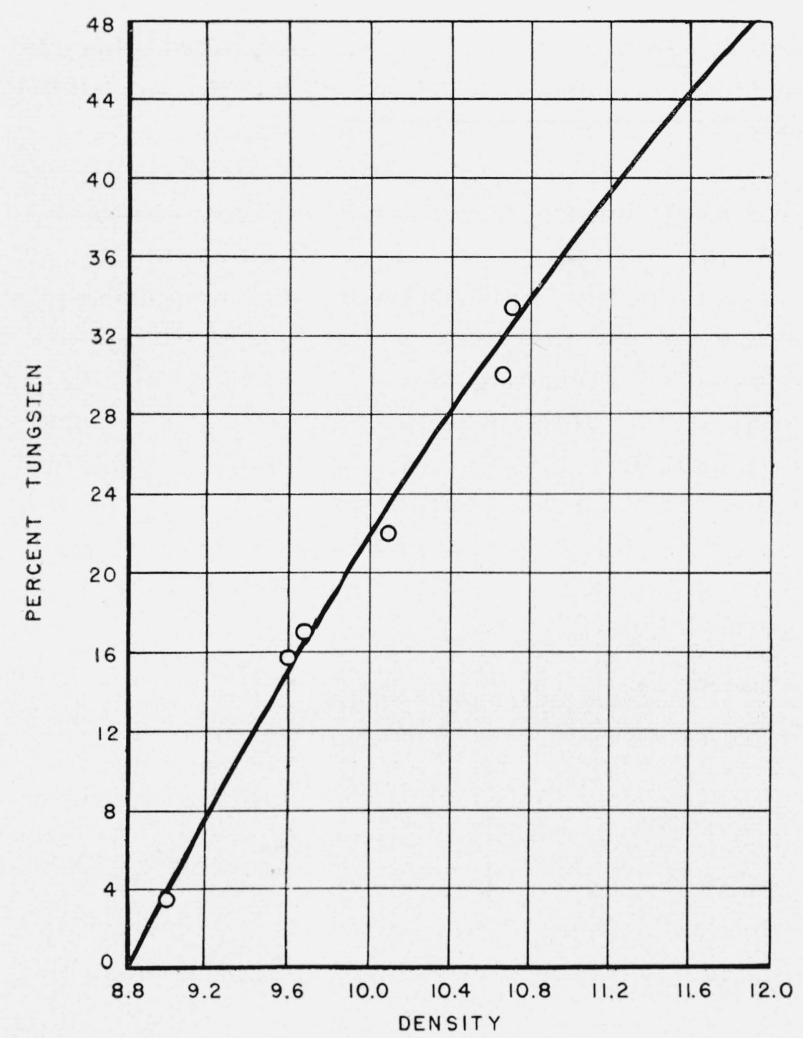

Figure 11.-Percent of tungsten in cobalt-tungsten or nickeltungsten alloys versus density.

The circles indicate the composition of electrodeposited tungsten alloys as determined by analysis.

TABLE 15.-YOUNG'S MODULUS OF ELECTRODEPOSITED TUNGSTEN ALLOYS

\begin{tabular}{|c|c|c|c|c|c|}
\hline No. & $\begin{array}{l}\text { Iron group } \\
\text { metal }\end{array}$ & Type of bath & $\begin{array}{l}\text { Tungsten } \\
\text { in deposit }\end{array}$ & \multicolumn{2}{|c|}{ Modulus } \\
\hline & & & Percent & $l b /$ in $.^{2} \times 10^{6}$ & $\mathrm{~kg} / \mathrm{mm}^{2} \times 10^{3}$ \\
\hline 1 & Co $\ldots$ & Tartrate. . & 15 & 24 & 17 \\
\hline 2 & $\mathrm{Co}$ & ..... do ..... & 25 & 25 & 17 \\
\hline 3 & $\mathrm{Ni}_{\text {.. }}$ & do & 5 & 23 & 16 \\
\hline 4 & $\mathrm{Ni} \ldots$ & Hydroxy acetate. & 17 & 25 & 17 \\
\hline 5 & $\mathrm{Ni}$ & Inorganic & 9 & 24 & 17 \\
\hline 6 & $\mathrm{Ni} . .$. & Tartrate & 15 & 11 & 8 \\
\hline 7 & $\mathrm{Fe}_{\text {... }}$ & Citrate & 46 & 25 & 17 \\
\hline 8 & $\mathrm{Fe}_{\ldots} .$. & _._._. do _... & 49 & 23 & 16 \\
\hline
\end{tabular}

seem to be about $17 \times 10^{3} \mathrm{~kg} / \mathrm{mm}^{2}$, which is lower than the modulus for the metals individually. (Moduli of the metals of the iron group are all about $21 \times 10^{3} \mathrm{~kg} / \mathrm{mm}^{2}$ and of tungsten, $36 \times 10^{3}$ $\mathrm{kg} / \mathrm{mm}^{2}$.

Fatigue Limit.-A few tests were run of the fatigue limit of a standard steel specimen plated with several thousandths of an inch of nickel- or cobalt-tungsten alloy. The steel used was X4130, which had a fatigue limit of $63 \mathrm{~kg} / \mathrm{mm}^{2}$. The alloys reduced the fatigue limit of the steel specimen to about $28 \mathrm{~kg} / \mathrm{mm}^{2}$, which is about the same result that is obtained with chromium coatings.

Frictional Properties.-No quantitative measurements of the coefficient of friction were made. However, in some qualitative experiments on galling in which the dry surfaces were rotated in contact under light loads, the cobalt-tungsten alloy behaved particularly well. This alloy has also been plated on small pivots and bearings, such as are used in instruments. Incomplete tests indicate that the performance of the alloy was satisfactory but not equal to that of jeweled bearings.

Electrical Properties.-The resistivities of cobalttungsten alloys of various compositions are given in table 16 . The resistivity varies almost linearly with the percentage of tungsten in the deposit (see fig. 12). Even after annealing, the resistivity of cobalt and of the tungsten alloys is still much

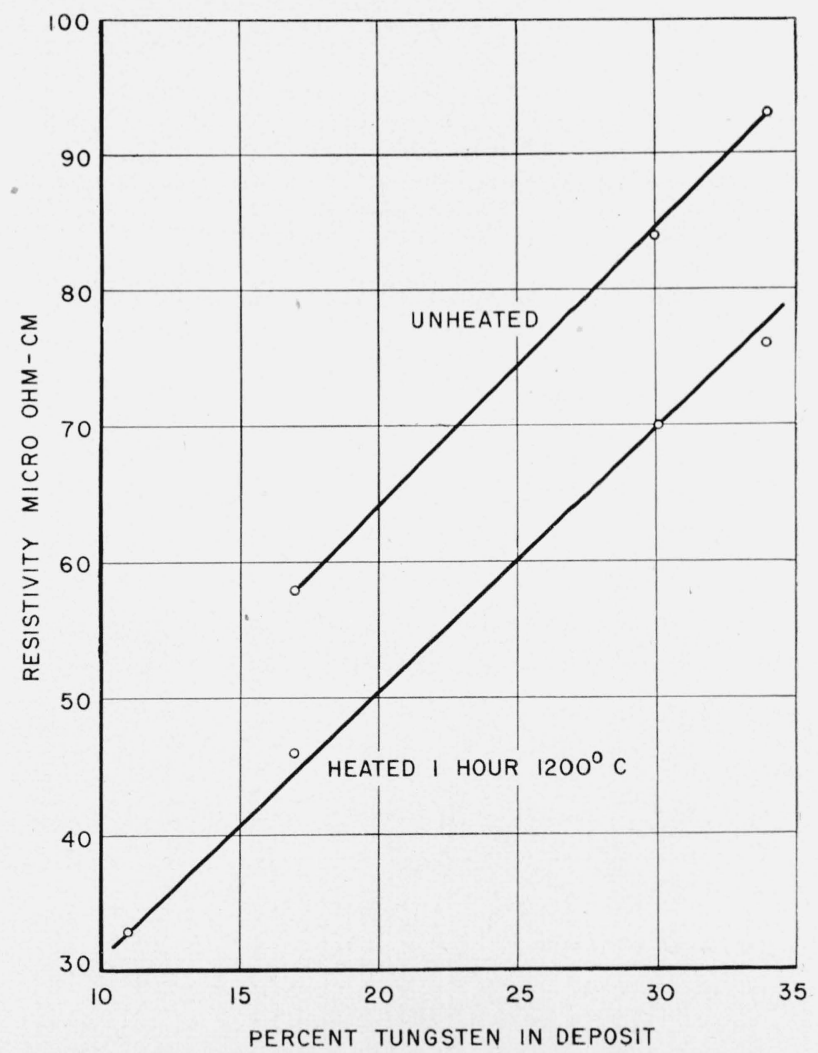

FIGURE 12.-Resistivity of electrodeposited cobalt-tungsten alloys versus percent of tungsten.

The resistivity is a linear function of the percentage of tungsten. 
TABLE 16.-Electrical resistivity of electrodeposited tungsten alloys

[Each solution contained Rochelle salt, $400 \mathrm{~g} /$ liter and ammonium chloride, $50 \mathrm{~g} /$ liter. Solutions were operated at $90^{\circ} \mathrm{C}$, with a $\mathrm{pH}$ of 8.5 to 9.0 and a current density of $2 \mathrm{amp} / \mathrm{dm}^{2}$.]

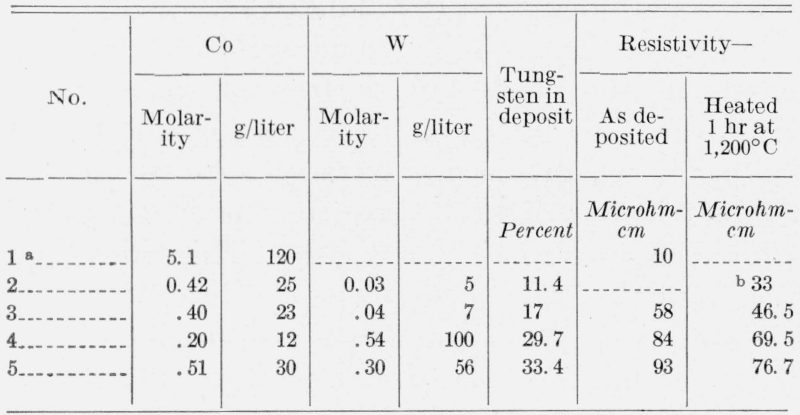

s Cobalt plating bath, $\mathrm{pH} 4$; no tungsten. $\quad \mathrm{b}$ Heated 1 hour at $1,000^{\circ} \mathrm{C}$. higher than that of the individual metallurgical metals. (Tungsten, 5.1; and cobalt 9.7 microhmcm.)

Magnetic Properties.-Most of the nickel-tungsten alloys containing above 20 percent of tungsten are not ferromagnetic. The dividing line is not sharp, and the plating conditions also have an effect on the magnetic properties of the alloys. The cobalt-tungsten alloys containing up to 30 percent of tungsten were magnetic. The irontungsten alloys were not consistent in magnetic behavior. Of those containing about 50 percent of tungsten, the majority were magnetic, but some were nonmagnetic, although they had been similarly plated.

TABLE 17.-Oxygen and hydrogen content of electrodeposited tungsten alloys

\begin{tabular}{|c|c|c|c|c|c|c|c|c|c|c|c|c|c|}
\hline \multirow{3}{*}{ No. } & \multirow{3}{*}{ Metal } & \multirow{2}{*}{\multicolumn{2}{|c|}{$\begin{array}{c}\text { Metal concentra- } \\
\text { tion }\end{array}$}} & \multirow{2}{*}{\multicolumn{2}{|c|}{ W }} & \multicolumn{3}{|c|}{ Salt } & \multirow{3}{*}{$\begin{array}{l}\text { Current } \\
\text { density }\end{array}$} & \multirow{3}{*}{$\begin{array}{l}\text { Temper- } \\
\text { ature }\end{array}$} & \multicolumn{3}{|c|}{ Composition of deposit } \\
\hline & & & & & & \multirow{2}{*}{ Type } & \multicolumn{2}{|c|}{ Concentration } & & & \multirow{2}{*}{$\begin{array}{l}\text { Tung- } \\
\text { sten }\end{array}$} & \multirow{2}{*}{ Hydro- } & \multirow{2}{*}{ Oxygen } \\
\hline & & Molarity & $\mathrm{g} /$ liter & Molarity & $\mathrm{g} /$ liter & & Molarity & g/liter & & & & & \\
\hline
\end{tabular}

INORGANIC

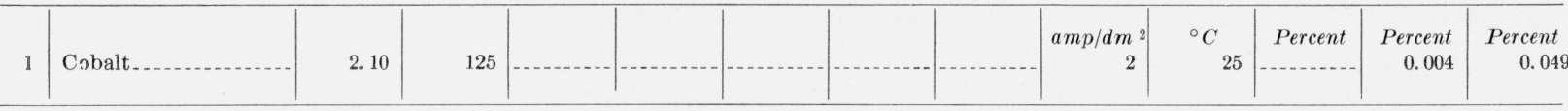

TARTRATE

\begin{tabular}{|c|c|c|c|c|c|c|c|c|c|c|c|c|c|}
\hline 2 & Cobalt_. & 0.42 & 25 & 0.03 & 5 & $\mathrm{Na}, \mathrm{K}$ & 1.40 & 400 & 2 & 90 & 14 & 0.011 & 0.08 \\
\hline 3 & ..... do_... & .42 & 25 & .03 & 5 & $\mathrm{Na}, \mathrm{K}$ & 1. 40 & 400 & 2 & 25 & 22 & .064 & 1.14 \\
\hline 4 & do do & .42 & 25 & .03 & 5 & $\mathrm{Na}, \mathrm{K}$ & 1.40 & 400 & 5 & 90 & 18 & .014 & 0.165 \\
\hline 5 & ........... & .42 & 25 & .14 & 25 & $\mathrm{Na}, \mathrm{K}$ & 1.40 & 400 & 2 & 90 & 25 & .008 & .087 \\
\hline 6 & .....do... & .42 & 25 & .27 & 50 & $\mathrm{NH}_{4}$ & 2. 00 & 370 & 2 & 90 & 23 & .009 & .064 \\
\hline \multicolumn{14}{|c|}{ CITRATE } \\
\hline 7 & Cobalt_. & 0.42 & 25 & 0.07 & 13 & $\mathrm{Na}$ & 0.60 & 200 & 2 & 90 & 42 & 0.027 & 0.430 \\
\hline 8 & ..... do ... & .42 & 25 & .03 & 5 & $\mathrm{NH}_{4}$ & 1. 20 & 300 & 2 & 90 & 20 & .012 & .177 \\
\hline
\end{tabular}

INORGANIC

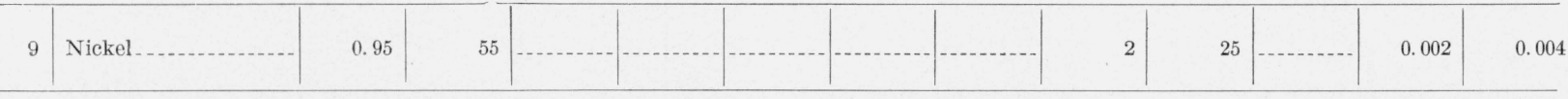

TARTRATE

\begin{tabular}{|c|c|c|c|c|c|c|c|c|c|c|c|c|c|}
\hline 10 & Nickel_. & 0.68 & 40 & 0.20 & $35^{2}$ & $\mathrm{Na}, \mathrm{K}$ & 0.70 & 200 & 2 & 90 & 5 & 0.004 & 0.006 \\
\hline $10 \mathrm{~A}$ & do & .68 & 40 & .20 & 35 & $\mathrm{Na}, \mathrm{K}$ & .70 & 200 & 2 & 25 & 13 & .042 & .360 \\
\hline
\end{tabular}

INORGANIC

\begin{tabular}{r|r|r|r|r|r|r|r|r|r}
\hline 11 & Iron & 2.0 & 110 & & & & & & \\
\end{tabular}

CITRATE

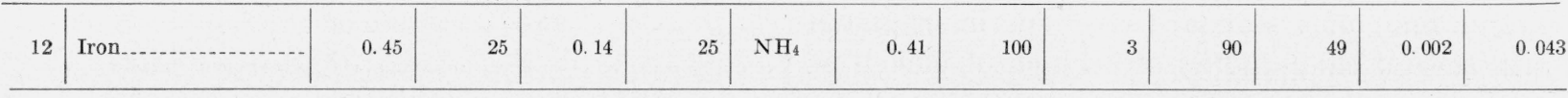


Reflectivity.-The specular reflectivity of polished nickel-tungsten alloys was found to range from 58 percent to 61 percent, which is close to that of nickel (60 percent).

\section{Chemical Properties}

Oxygen Content of the Alloys.-The oxygen content of electrodeposited metals is of importance, as a high oxygen content indicates that much basic matter is being included in the deposit. Deposits with a high-oxygen content usually have inferior physical properties, such as brittleness and low strength. Table 17 shows some results for tungsten alloys along with cobalt and nickel for comparison. The oxygen content of the alloys is slightly higher than that of the iron group metals deposited separately.

From table 17 it is seen that Co-W deposits from citrate solutions have a higher oxygen content than those from tartrate solutions (compare 7 and 8 with 2 and 6 ); and deposits from solutions made up with ammonium salts of the organic acids have a lower oxygen content than from those containing the sodium salts (compare 5 and 6 ; and 7 and 8 ). Deposits plated at room temperature have a large content of oxide inclusions (No. 3 and 10A), which explains why they are so unsound.

The hydrogen content of the deposits ranges from 1 to 3 times the amount necessary to combine with the oxygen as $\mathrm{OH}$ groups.

Carbon Content.-When hardening of these alloys on heating was first observed, it was believed to be caused by the formation of tungsten carbide from the carbon that might be included in the deposits. It was known that some bright nickel deposits which are plated from solutions containing organic addition agents contain several tenths of a percent of carbon [21]. The analyses of some typical nickel- and cobalt-tungsten alloys showed that the deposits contained less than 0.01 percent of carbon, and therefore the hardening could not have been caused by the presence of carbon.

Attack of Cobalt-and Nickel-Tungsten Alloys by Reagents.-The attack of nickel- and cobalttungsten alloys by hydrochloric, nitric, sulfuric, and acetic acids, and by solutions of ammonium chloride and ammonium hydroxide was compared with the action of these reagents on the unalloyed electrodeposited metals. The cobalt alloys behaved very similarly to electrodeposited cobalt, and the nickel alloys showed slightly less attack than electrodeposited nickel. The data are shown in table 18, which contains the average results for alloys of three different compositions. On the basis of the chemical inertness of tungsten a greater resistance to chemical attack was expected of the alloys. The resistance of the alloys to solution by nitric acid seems to be the chief difference from the electrodeposited cobalt and nickel.

TABLE 18. Attack of cobalt- and nickel-tungsten alloys by chemical reagents

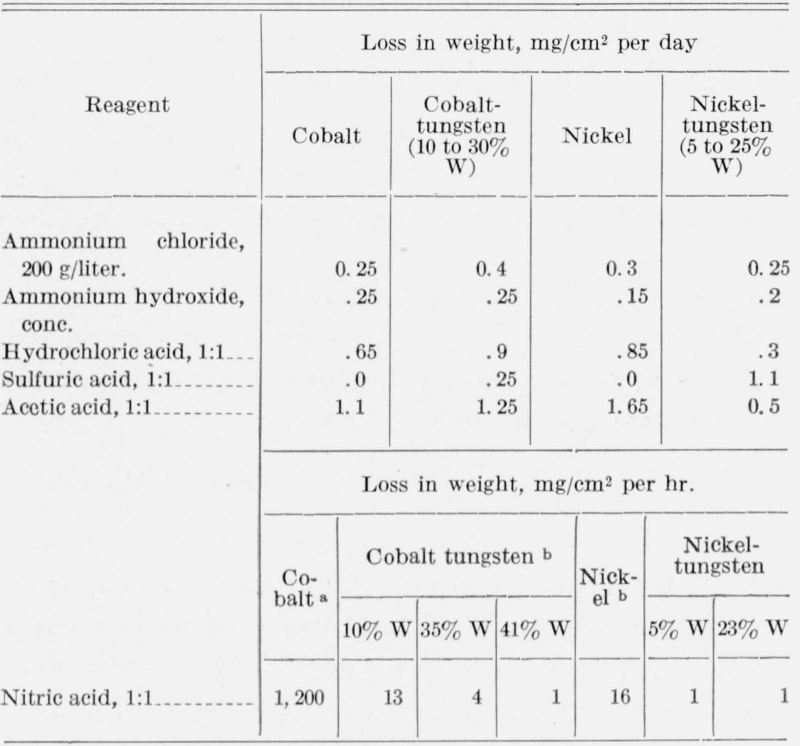

s Based on 10-min test.

b Based on 4-hr test.

\section{Protective Value of Alloy Coatings on Steel}

Flat steel panels, plated with cobalt-tungsten and nickel-tungsten alloys of three different compositions were subjected to the salt spray for 5 days, along with similar panels plated with nickel and cobalt alone. The coatings had the following thicknesses: $0.006,0.013$, and $0.025 \mathrm{~mm}(0.00025$, 0.0005 , and $0.001 \mathrm{in}$.). The cobalt and cobalttungsten alloy panels (see fig. 13) showed superior protective value to nickel or nickel-tungsten alloys (see fig. 14), the cobalt alloy coatings being the better. The break-down of the panels in all cases resulted from the porosity of the coatings. The nickel coatings showed the usual degree of porosity, which varied from a liberal sprinkling of a hundred or more spots per square decimeter on the thin coating to several pores per square decimeter on the thicker coatings. The behavior of the thin cobalt-tungsten alloy coatings 


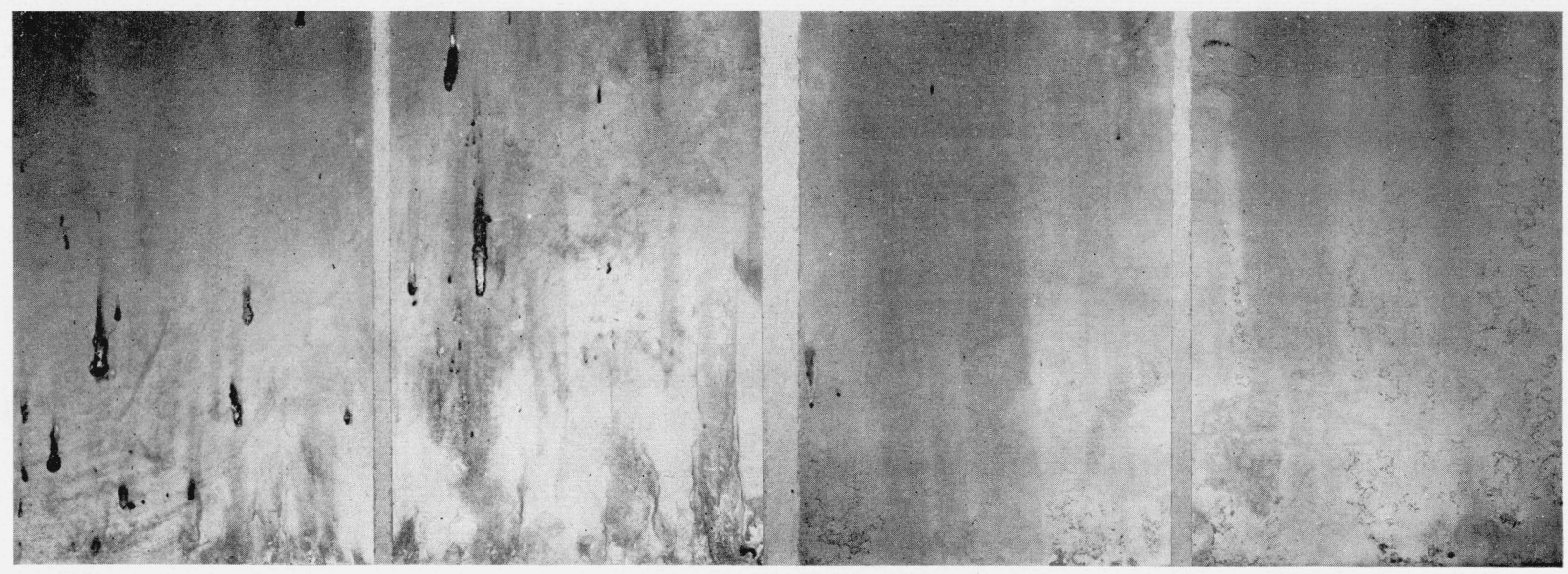

FIGURE 13. Appearance of steel panels, plated with cobalt and with cobalt-tungsten alloy (20 percent tungsten), after an exposure of 5 days to the 20-percent salt-spray test.

The first two (left) are plated with cobalt and the last two (right) with alloy. Thickness of coatings, first and third: $0.006 \mathrm{~mm}$ (0.00025 in.); second and fourth, $0.025 \mathrm{~mm}(0.001 \mathrm{in}$.).

was outstanding; after 5 days of exposure to the salt spray, they did not develop more than a few pores and were in much better condition than the thick coatings of nickel (see fig. 13).

\section{Field of Application of Tungsten Alloys}

The tungsten alloys should find applications where hardness, particularly at elevated temperatures, is required. They may be competitive with chromium and hard nickel for building up worn parts or for use in dies. The good throwing power of these alkaline plating solutions should make the plating of many objects with tungsten alloy much simpler than with chromium, as complicated anodes would not be required. Sug- gested fields of application are on bearings, tools, pistons, cylinders, and dies.

The main disadvantage involved in the plating of these alloys is that the operating conditions require elevated temperatures, and continual addition of ammonia to maintain the $\mathrm{pH}$ is necessary.

The authors acknowledge the advice and guidance of William Blum, chief of the Electroplating Section, and the assistance of Grace E. Riddell and Clara A. Sentel, who did some of the earlier work on the plating of the alloys. The authors are indebted to members of other Divisions of the National Bureau of Standards for the measure-
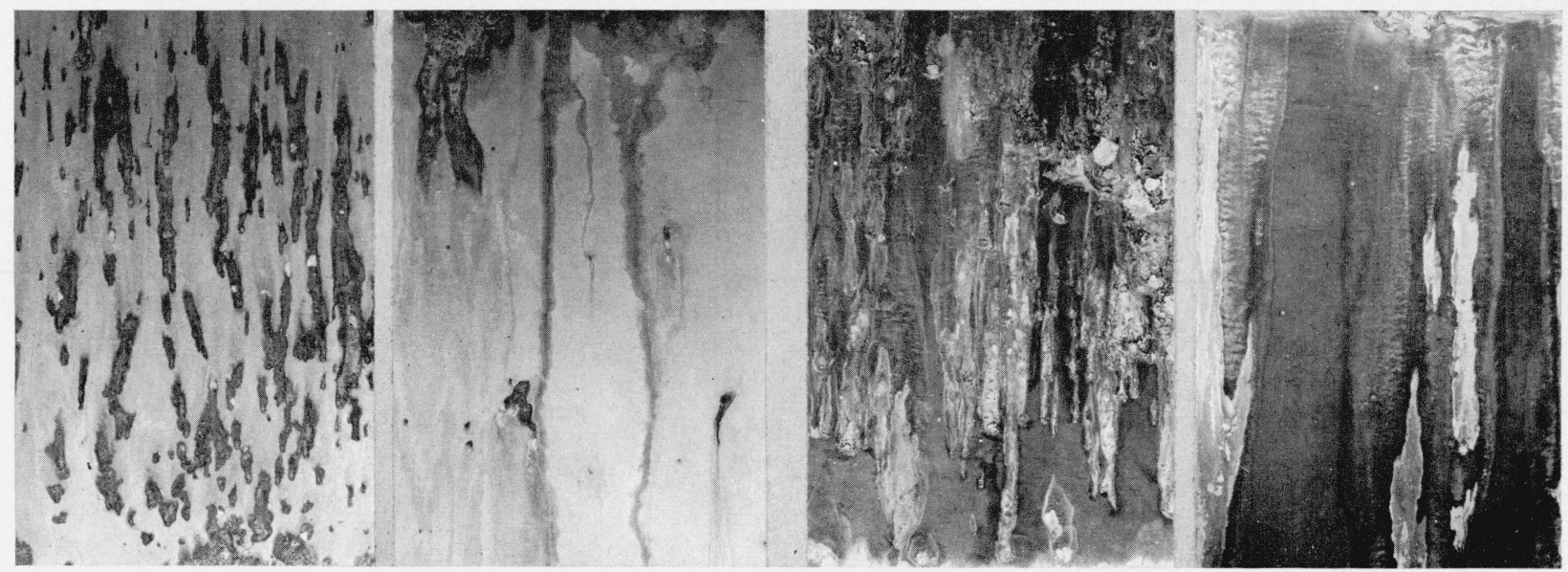

FIgURE 14. Appearance of steel panels, plated with nickel and with nickel-tungsten alloy an exposure of 5 days to the 20-percent salt-spray test.

The first two (left) are plated with nickel and the last two (right) with alloy. Thickness of coatings, first and third: $0.006 \mathrm{~mm}(0.00025 \mathrm{in}$.); second and fourth, $0.025 \mathrm{~mm}(0.001 \mathrm{in}$.$) .$ 
ment of some of the properties of the alloys, particularly H. E. Cleaves for the measurements of the oxygen and hydrogen content, to William E. Roeser for measurements of hardness, to H. C. Vacher for X-ray examination, and to Peter Hidnert for coefficient of thermal expansion. The authors acknowledge the assistance of A. F. Osborn of the Geophysical Laboratory, who examined the alloy deposits in the earlier stages of the work.

\section{References}

[1] U. S. Patent 2,145,241 (Jan. 31, 1939).

[2] U. S. Patent 2,145,745 (Jan. 31, 1939).

[3] U. S. Patent 2,145,746 (Jan. 31, 1939).

[4] U. S. Patent 2,160,321 (May 30, 1939).

[5] U. S. Patent 2,160,322 (May 30, 1939).

[6] British Patent 460,886 (Feb. 1937).

[7] British Patent 460,931 (Feb. 1937).

[8] British Patent 478,640 (Jan. 1938).

[9] P. P. Belyaev and A. I. Lipovetskaya, Korroziya i Borba s Nei 6, 247 (1940).

[10] R. L. Dowdell, H. S. Jerabek, A. C. Forsyth, and C. H. Green, General metallography (John Wiley \& Sons, Inc., 1943). (Co-W diagram, p. 279; Fe-W diagram, p. 281; Ni-W diagram, p. 282).

[11] Finley H. Ellinger and Wesley P. Sykes, Trans. Am. Soc. Metals 28, 619 (1940).
[12] B. S. Evans, The analyst 62, 363 (1937).

[13] C. G. Fink, and Frank L. Jones, Trans. Electrochem. Soc. 59, 461 (1931).

[14] L. N. Golotz and V. N. Kharlamov, J. Applied Chem. (USSR) 9, 640 (1936).

[15] M. L. Holt, Trans. Electrochem. Soc. 66, 453 (1934).

[16] M. L. Holt, Trans. Electrochem. Soc. 71, 301 (1937).

[17] M. L. Holt and M. L. Neilsen, Trans. Electrochem. Soc. 82, 193 (1942).

[18] M. L. Holt, R. E. Black, and P. F. Hoglund, Trans. Electrochem. Soc. 84, 353 (1943).

[19] M. L. Holt and R. E. Black, Trans. Electrochem Soc. 82, 205 (1942).

[20] M. L. Holt and D. A. Swalheim, Trans. Electrochem. Soc. 81, 251 (1942).

[21] A. E. Hothersall and G. E. Gardam, J. Electrodepositors' Tech. Soc. 15, 127 (1939).

[22] S. I. Sklyarenko, O. S. Druzhinina, and M. M. Masal'tseva, J. Applied Chem. (USSR) 13, 1326 (1940).

[23] Wesley P. Sykes, U. S. Patent 2,050,865 (Aug. 11 1936).

[24] Wesley P. Sykes, Trans. Am. Soc. Metals 25, 95i (1937).

[25] L. E. Vaaler and M. L. Holt, Trans. Electrochem. Soc. 90, $15 \mathrm{P}$ (1946).

[26] G. Wasserman, Metall. Wirtschaft 11, 61 (1932).

[27] W. A. Wesley and E. J. Roehl, Trans. Electrochem. Soc. 8\%, 37 (1942).

Washington, April 9, 1947. 